NBER WORKING PAPER SERIES

THE SHAPE OF TEMPTATION: IMPLICATIONS FOR THE ECONOMIC LIVES OF THE POOR

\author{
Abhijit Banerjee \\ Sendhil Mullainathan \\ Working Paper 15973 \\ http://www.nber.org/papers/w15973
NATIONAL BUREAU OF ECONOMIC RESEARCH
1050 Massachusetts Avenue
Cambridge, MA 02138

May 2010

We are grateful to Doug Bernheim, Pierre-Andre Chiappori, Esther Duflo, David Laibson, Dilip Mookherjee, Adriana Lleras-Muney, Ben Polak, Matthew Rabin and seminar participants at BREAD, Cornell, Columbia, Bocconi, Stanford, Warwick, Yale, Princeton, UCLA, Harvard, MIT, Pompeu Fabra, Unviversidad Carlos III de Madrid, The Trento Summer School on Behavioral Economics, and Boston University for extremely helpful comments. We are particularly grateful to Daniel Benjamin and Ted O'Donoghue for posing challenges on an earlier draft that led to significant changes in this one and to Arun Chandrasekhar and Emily Breza for superb research assistance. The views expressed herein are those of the authors and do not necessarily reflect the views of the National Bureau of Economic Research.

NBER working papers are circulated for discussion and comment purposes. They have not been peerreviewed or been subject to the review by the NBER Board of Directors that accompanies official NBER publications.

(C) 2010 by Abhijit Banerjee and Sendhil Mullainathan. All rights reserved. Short sections of text, not to exceed two paragraphs, may be quoted without explicit permission provided that full credit, including (c) notice, is given to the source. 
The Shape of Temptation: Implications for the Economic Lives of the Poor Abhijit Banerjee and Sendhil Mullainathan

NBER Working Paper No. 15973

May 2010

JEL No. D03,D91,O12

\begin{abstract}
$\underline{\text { ABSTRACT }}$
This paper argues that the relation between temptations and the level of consumption plays a key role in explaining the observed behaviors of the poor. Temptation goods are defined to be the set of goods that generate positive utility for the self that consumes them, but not for any previous self that anticipates that they will be consumed in the future. We show that the assumption of declining temptations, which says that the fraction of the marginal dollar that is spent on temptation goods decreases with overall consumption, has a number of striking implications for the investment, savings, borrowing and risk-taking behavior of the poor, which would not arise if temptations were either non-declining or entirely absent. Moreover the predicted behaviors under the declining temptation assumption can help us explain some of the puzzling facts about the poor that have been emphasized in the recent literature.
\end{abstract}

\author{
Abhijit Banerjee \\ MIT \\ Department of Economics \\ E52-252d \\ 50 Memorial Drive \\ Cambridge, MA 02142-1347 \\ and NBER \\ banerjee@mit.edu \\ Sendhil Mullainathan \\ Department of Economics \\ Littauer 208 \\ Harvard University \\ Cambridge, MA 02138 \\ and NBER \\ mullain@fas.harvard.edu
}




\title{
The Shape of Temptation: Implications for the Economic Lives of the Poor*
}

\author{
Abhijit V. Banerjee \\ MIT, BREAD, CEPR, NBER \\ Sendhil Mullainathan \\ Harvard University, BREAD, NBER
}

April 2010

\begin{abstract}
This paper argues that the relation between temptations and the level of consumption plays a key role in explaining the observed behaviors of the poor. Temptation goods are defined to be the set of goods that generate positive utility for the self that consumes them, but not for any previous self that anticipates that they will be consumed in the future. We show that the assumption of declining temptations, which says that the fraction of the marginal dollar that is spent on temptation goods decreases with overall consumption, has a number of striking implications for the investment, savings, borrowing and risk-taking behavior of the poor, which would not arise if temptations were either non-declining or entirely absent. Moreover the predicted behaviors under the declining temptation assumption can help us explain some of the puzzling facts about the poor that have been emphasized in the recent literature.
\end{abstract}

JEL Codes D03, D91, O12

\section{Introduction}

The poor often behave as if they are very myopic. For example, they borrow repeatedly at extremely high interest rates ${ }^{1}$ which, at least under the standard

\footnotetext{
*We are grateful to Doug Bernheim, Pierre-Andre Chiappori, Esther Duflo, David Laibson, Dilip Mookherjee, Adriana Lleras-Muney, Ben Polak, Matthew Rabin and seminar participants at BREAD, Cornell, Columbia, Bocconi, Stanford, Warwick, Yale, Princeton, UCLA, Harvard, MIT, Pompeu Fabra, Unviversidad Carlos III de Madrid, The Trento Summer School on Behavioral Economics, and Boston University for extremely helpful comments. We are particularly grateful to Daniel Benjamin and Ted O'Donoghue for posing challenges on an earlier draft that led to significant changes in this one and to Arun Chandrasekhar and Emily Breza for superb research assistance.

${ }^{1}$ For example, Aleem (1990) in a survey of money lenders finds an average interest rate of $78.5 \%$ per year. Even formal micro-financial institutions charge extremely high rates. In
} 
model of consumption decision-making, suggests a strong preference for consuming today rather than tomorrow. For example, if individuals are consuming at steady state levels, the Euler inequality

$$
u^{\prime}\left(c_{t}\right) \geq \delta R u^{\prime}\left(c_{t+1}\right)
$$

implies that $\delta \leq \frac{1}{R}$, which, if $R$ is high, puts a rather stringent upper bound on $\delta$. Of course, the steady state assumption may be incorrect. Out of steady state, a high $R$ would be consistent with a $\delta$ close to 1 , but only if consumption is growing fast-in other words, if the poor are rapidly becoming non-poor. This, however seems counterfactual-for example, Karlan and Mullainathan (2009) provide evidence that small-time fruit vendors in Chennai. India, pay interest rates of $5 \%$ per day to finance their business, have been doing so for nine years on average and remain very poor. ${ }^{2}$ The same fact is reinforced by evidence from the investment domain. Estimates of returns to capital for very small firms suggest high rates of return for divisible investments. (See de Mel, McKenzie, and Woodruff (2008) on returns to capital in micro-enterprises in Sri Lanka, Lee, Kremer and Robinson (2009) on returns to holding more inventories in Kenya, Duflo, Kremer and Robinson (2009) on using fertilizer in Kenya and Udry and Anagol (2006) on crop choices in Ghana). Once again, the decision to consume today rather than take up these high return investment activities suggests a high discount rate.

It is theoretically possible explain these phenomena based on non-standard assumptions about the form of the utility function, but these alternative explanations do not seem to be particularly empirically plausible. For example, one could argue that the poor cannot cut back on consumption because they are against some sort of "minimum consumption" constraint. This, however, appears implausible given (a) that consumption actually shows substantial high frequency variation (Collins et. al. (2009)) and (b) the direct evidence (see Banerjee and Duflo (2007)) that even the very poor spend a significant part of their income on what are clearly not survival necessities (cigarettes, alcohol, expensive but not especially nutritious foods). Another argument is that the realized discount factor is a consequence of high mortality. The problem is that death rates for a very poor person at age 30 or 40 is not substantially different from that of someone richer. A very different alternative is to argue that the interest rates are not realized because of high default rates. In fact however default rates for both formal and informal institutions that actually lend to the

Mexico and other countries, for example, prominent micro-finance institutions charge $90 \%+$ per year. The fact that people are borrowing at these rates repeatedly is reported for the case of agricultural finance by Dreze, Lanjouw and Sharma (1997), the case of daily working capital by Karlan and Mullainathan (2009) and for payday loan usage in the United States by Skiba and Tobacman (2007). See Banerjee (2004) for a survey of the evidence of high interest borrowing in developing countries.

${ }^{2}$ This example also rules out the possibility that the high interest rate borrowing is simply emergency borrowing, i.e. borrowing in unusual states of the world when the marginal utility of consumption is especially high. Much of the litarature on how interest rate borrowing also emphasizes the fact that such borrowing is entirely routine for many low income borrowers (see survey of the evidence in Banerjee (2004)). 
poor are extremely low (Banerjee (2004)). Default rates for all the lenders in Aleem's study are below $10 \%$ and the median is less than $5 \%$. This is also the shared experience of Microfinance Institutions.

In this paper, we provide an alternative approach. We builds on a growing literature which models myopic behavior as part of a broader set of time inconsistent preferences (Shefrin and Thaler (1981), Laibson (1997), O'Donoghue and Rabin (1999)) and points out that for many people, myopia about some decisions coexists with being farsighted about others. The poor are no different in this regard: The same people that borrow at very high rates also engage in various far-sighted behaviors, from the purchase of burial insurance to participation in ROSCAs (Collins et. al. (2009)).

At the core of our model of self-control is the assumption that there are two types of goods-goods that generate utility both when consumed but also before they are consumed (i.e. in anticipation) and goods which, to a much greater extent, generate utility only at the point of consumption. We may take great pleasure from smoking a cigarette today or eating a whole box of donuts, but knowing that we will consume them in the future even though they are bad for us does not make us happy (and indeed, may even serve to get us depressed).

In our framework, the donut or the cigarette represents a temptation good. In the moment we would spend money on it. But we would like future selves to not spend money on it. Temptation goods give us utility in the moment but it is not utility we care for when considering future selves. ${ }^{3}$ This is in alternative to other goods where present and future selves agree: in the moment we spend on them and we would like future selves to spend on them as well. These are goods like a good education for our child, our a nice house to retire in.

The link to poverty within this framework comes from assuming that the fraction of the marginal dollar that is spent on temptation goods can depend on the level of consumption. In particular we distinguish between the case where temptation is declining in the sense that the above-mentioned fraction goes down as total consumption goes up and the case where it either stays the same or goes up (the non-declining temptation case). We postpone a more detailed discussion of why temptation might be declining (or not) till the next section. However one motivating example might help to see why temptations do not have to scale with income: Suppose that donuts that cost $\$ 0.25$ form a visceral temptation that tempt all people equally. Giving in to this temptation, however, has different budgetary impacts for the rich and the poor. The $\$ 0.25$ will be far more costly to someone living on $\$ 2$ a day than to someone living on $\$ 30$ a day. In other words, the same self-control problem is more consequential for the poor. This example generalizes even if the rich face new temptations so long as the temptations they face do not rise proportionally with income, which may be the case, for example, because temptation goods are better at satisfying primitive consumption urges-fat, sugar, and other visceral pleasuresthan other forms of consumption. It is not implausible that such urges may

\footnotetext{
${ }^{3}$ As discussed below, a very similar formulation can arise from a model of family decisionmaking with divergent preferences.
} 
(after a certain wealth level) be easily satisfied and that further expenditure is unlikely to produce much more pleasure. ${ }^{4}$ As a practical matter, donuts can only get so expensive (and even then only gain very little in "temptingness"). When the availability of temptations do not increase proportionally with income, then the poor will spend a bigger share of their marginal dollar on "temptation goods" 5

Of course in the end, whatever assumption we make about the shape of temptations must be judged by how well it fits the data. The main point of this paper is that the assumption of declining temptation has a number of striking and novel implications that are relevant to understanding the savings, credit, risktaking and investment choices made by the poor and how the poor get treated in asset markets. This contrasts with the case of non-declining temptation, where the standard intuitions mostly continue to hold, despite the fact this is a model that allows for self-control problems in the decision process.

To formalize these idea that some goods are more tempting than others, ${ }^{6}$ we expand the standard hyperbolic model-which focuses on time inconsistency in the level (not composition) of consumption $c_{t}$ arising from discount factors which vary by horizon-to consider the case where there are two goods. Consumption $c_{t}$ has two components; $x_{t}$ and $z_{t}$. The first, $x_{t}$, reflects consumption spending on which there is no temptation: $x_{t}$ has prospective value for all periods $s \leq t$. The second, $z_{t}$, reflects consumption where there is temptation; only the $t$ self values $z_{t}$, i.e. there is no prospective valuation of $z$ consumption. We refer to $x$ as a non-temptation good and $z$ as a temptation good. ${ }^{7}$

Interestingly, time inconsistency now arises even without horizon-varying discount factors. Simply allowing the different goods to have different discount rates already produces time inconsistency because these different discount factors generate disagreement over the two selves about the composition of consumption. In other words, our framework extends the logic of the hyperbolic model to the case of multiple goods-with an emphasis on good-specific rather than horizon-specific discount factors. ${ }^{8}$

\footnotetext{
${ }^{4}$ In fact data from India on spending on oils, fats and sugars in fact suggests that while they are an increasing share of food expenditures, they are actually a decreasing share of total expenditures (see for example Subramanian and Deaton (2006)).

${ }^{5}$ Of course some might argue that at least a part of the lack of self-control is intrinsic to being poor: perhaps lack of health or human capital investments at an early age reduces development of the facility of self-control. For example, Becker and Mulligan (1997) provide a framework to understand the endogenous determination of discount rates, though not necessarily self-control. This is however not the approach we take.

${ }^{6}$ Experimental evidence for the idea that some goods are more tempting can be found in among others Read, Loewenstein and Kalyanraman (1999). See also O'Donoghue and Rabin (2006).

${ }^{7}$ Such good-specific temptations could also be captured in a hyperbolic model by allowing goods to deliver different types of consumption at different points in time (as in Gruber and Koszegi (2001) on cigarettes). While an excellent framework for understanding situations where the main issue is the long-run consequences of a good (e.g. health effects), such an appraoch is less appealing when we are interested purely in how the consumption of temptation goods affects savings etc.

${ }^{8}$ In Section 4.2 , we examine in what way a more standard hyperbolic model, without consideration of good-specific discount factors, could generate income-dependent self-control
} 
This disagreement over composition also generates disagreement over the level of consumption. Formally, consumption choices in this model are determined by a modified Euler equation:

$$
u^{\prime}\left(x_{t}\right)=\delta R u^{\prime}\left(x_{t+1}\right)\left[1-z^{\prime}\left(c_{t+1}\right)\right]
$$

where $z(c)$ quantifies the amount of total consumption that goes to temptation goods. So spending tomorrow is subject to a "temptation tax": a dollar spent tomorrow is partly dissipated on temptation goods. Since today's self does not value tomorrow's temptation spending, any temptation spending tomorrow is a waste. As a result, today's self would prefer to consume more today rather than save, producing what appears to be a high discount factor. ${ }^{9}$

A number of conclusions follow directly from this simple equation and the reasoning that goes into it. For example, it can explain why the poor may much appear much more patient in the purchase of durable goods than in their savings decisions, and why "sin" taxes may have undesirable effects on decision-making by the poor. However the most important value added of our framework comes from being able to precisely define what we called the declining temptation case: This is the case where $z^{\prime}(c)$ is decreasing and hence $z(c)$ is concave. The paper is primarily about the implications of this assumption, some of which are listed below

First, it is evident from the Modified Euler Equation and the fact that $z(c)$ is concave, that if we use the traditional Euler equation to back out discount factors, the poor will appear to be more myopic than the non-poor even if they are not. ${ }^{10}$ What appears to be myopic behavior amongst the poor is as much a result of their poverty as it is a cause.

Second, a concave temptation tax alone can generate a behavioral poverty trap. In this case, there will exist a critical initial wealth level $\underline{w}>0$ such that long run consumption discontinuously jumps up around $\underline{w}$. Those individuals with wealth just below $\underline{w}$ will save very little or dissave, while those who are slightly wealthier will save a lot more. Note that this poverty trap arises even though we have no lumpy investments or even credit constraints, the usual ingredients of models of poverty traps. Intuitively, in our model, individuals face an added incentive to save because if they get richer, the temptation tax goes down. On the other hand, at low enough wealth, this added incentive is offset by the level of the temptation tax. Put another way, the moderately well-off can save in the hopes of being sufficiently wealthy to avoid a large tax. The poor cannot save enough to accomplish this (or in a multi-period model it would take them too long do so); hence they simply dissave. People are presentbiased because they are poor, but that in turn keeps them poor. More generally, giving people some reason to be hopeful about the future makes them act more

factors.

${ }^{9}$ In our formal model, the temptation tax is central. Our model could be reinterpreted also as arising from some family-conflict models. We do not attempt to make a distinction from this interpretation.

${ }^{10}$ In the economics literature, the fact that the poor appear ro be myopic was remarked upon as early as Irving Fisher (1932). 
forward-looking in the present, which might actually end up partially justifying the hope (this therefore has the flavor of an aspiration effect (Ray (2002)). This effect and hence the poverty trap cannot exist under non-declining temptations.

Third, a concave temptation tax affects individuals' responses to uncertainty: Individuals may hold very little buffer stock savings relative to the shocks they face. This is because they fear that the future selves will spend liquid savings on temptation goods. The model also has surprising implications for precautionary savings behavior: an increase in variance can actually reduce precautionary savings. This is true even if the utility functions (both $u(x)$ and $v(z)$ ) exhibit prudence.

Fourth, investment behavior in this framework will be constrained not just by returns and the minimum admissible scale associated with the project, but also by the maximum possible scale: a small high return investment may not be as attractive as a larger opportunity with lower returns. This, we feel, can help explain phenomena such as why individuals fail to undertake very high return non-lumpy investments that are available to them (we already mentioned Duflo, Kremer and Robinson's work on fertilizer and Lee, Kremer and Robinson's research on working capital). Once again this cannot happen as long temptations are non-declining.

The model also has implications for the demand for credit. While predicting that there will be a desire for commitment (a cap on loan sizes) as in any model of time inconsistency with sophistication, it also notes this desire is not monotonic: people may prefer their future selves to take a bigger loan over a smaller one if temptations are declining but not otherwise

Finally, this model allows us to think about why, even in the absence of enforcement problems or asymmetric information, a lender who has full market power may refuse to finance a borrower who has a profitable investment opportunity that generates a net surplus over the cost of capital. Specifically, we show that given these preferences, monopolistic money-lenders might have the incentive to deny certain individuals otherwise profitable loans in order maintain their power over the borrower. As pointed out by Srinivasan (1979), this is not possible with standard preferences-nor with non-declining temptations, as we show. ${ }^{11}$

The next section presents our model, explains the modeling of the self-control problem and derives its basic properties. In particular we derive and the explain the Modified Euler Equation. The next section presents implications of the Modified Euler Equation, without introducing the declining temptation assumption. Section 4 introduces, explains and motivates the declining temptation assumption. Section 5 derives a series of consequences of the declining temptations assumption and contrasts them with the non-declining temptation case. Each sub-section of section 5 is an application of this assumption to a different problem of saving, investment or credit. Finally, while these results are qualitative and the primary value of this paper is its ability to deliver a number implications from a simple assumption, section 6 discusses some potentially

${ }^{11}$ The idea of trying to formalize this debt trap goes back to Bhaduri (1977). 
quantitative tests of the model.

\section{Model}

\subsection{Modeling Temptations}

Before setting up the model in full generality, we describe a simple version that captures the main intuitions. Suppose that an individual lives for two periods $t=1,2$. Each period, he can consume $x_{t}$ and $z_{t}$, two different components of consumption. ${ }^{12}$ If individuals were time consistent and had separable utility functions, they would maximize $U\left(x^{1}\right)+V\left(z^{1}\right)+\delta U\left(x^{2}\right)+\delta V\left(z^{2}\right)$. The two goods produce different utility and the two time periods have different value: today's self favors today over tomorrow. But the two selves agree on how to weight the different goods. By contrast, in our model, temptation goods are exactly those goods about which today's self and tomorrow's self disagree. A stark way to model this is to assume that the period 1 self maximizes

$$
U\left(x^{1}\right)+V\left(z^{1}\right)+\delta U\left(x^{2}\right) .
$$

In other words, he values his own spending on temptation goods but does not value tomorrow's self's spending on them. One rationale for this is that hedonic experiences can be multi-dimensional. Some hedonic experiences provide visceral, immediate pleasures. For example, sugary or fatty foods may provide such instant gratification. Other experiences provide different more lasting pleasures. For example, eating a more healthy meal may provide a sense of fullness and some pleasurable tastes but not the same instant gratification. If we value instant gratification more in the moment than we do for future selves, then a self-control problem arises. ${ }^{13}$ Others have argued that the neurological evidence favors a two-self model in which one self is tempted by visceral pleasures and the other is focused on longer term consumption (Fudenberg and Levine (2006)). Our work can be thought of as a particular way to model this disjunction.

A different rationale comes from the nature of social pressures: People often feel obliged to subsidize certain relatives but take no pleasure in doing so. For someone who takes no enjoyment in anticipating that she will subsidize a particular relative in the future, the maximization is exactly the one above, with money for the relative modeled as a $z$ good. More generally consider a family (or an extended family) where savings decisions are controlled by one member but the division of total consumption spending across different goods is negotiated among the various different constituents. In this case the $x$ good is the part of total family consumption that the person who is in charge of the savings values, while the rest is are $z$ goods. We do not aim to distinguish from this form of family conflict from intra-personal conflicts.

\footnotetext{
${ }^{12}$ Note in what follows these two components will be two different amounts of money spent on consumption.

${ }^{13}$ This interpretation is bolstered by recent neurological research which argues that immediate pleasures and the resulting self-control problem may be localized in different parts of the brain (see McClure et. al. (2004)).
} 
The particular modeling approach we take offers three main advantages. It allows us to introduce between-good variation in the extent of the self-control problem associated with the goods. Second, it allows us to capture the idea that self-control problems vary by the level of consumption in a very simple way. Third, it allows us to introduce self-control problems in a two period model, unlike in the standard hyperbolic discounting model (where individuals maximize a utility function of the form $\left.u\left(c_{0}\right)+\beta \sum_{t} \delta^{t} u\left(c_{t}\right)\right)$.

We do not claim that these ideas cannot be captured in other, more standard, models of time inconsistency. As we discuss in section 3.1, the idea that temptations vary with the level of consumption, for example, can be captured in the hyperbolic discounting framework but the conditions required to get the property are significantly less transparent than the conditions we need to impose and therefore harder to judge.

The more general version of our model simply recognizes that when there are several goods, one can form an index of spending on temptation goods and an index of spending on non-temptation goods. ${ }^{14}$ To capture these ideas, suppose there are $\mathrm{n}$ goods consumed in each of two time periods. ${ }^{15}$ Denote the amount consumed of good $i=\{1,2 \ldots . m, m+1, \ldots . n\}$ in time $t=\{1,2\}$ by $x_{i}^{t}$. At time 2 individuals maximize:

$$
E\left\{\widetilde{U}\left(x_{1}^{2}, \ldots, x_{m}^{2}\right)\right\}
$$

where the $\tilde{U}$ is increasing and concave, and $E\{\cdot\}$ is the expectations operator defined in terms of the uncertainty in the model, as defined below.

At time 1, we assume individuals have decision utility equal to:

$$
\widetilde{U}\left(x_{1}^{1}, \ldots, x_{m}^{1}\right)+\widetilde{V}\left(x_{m+1}^{1}, \ldots, x_{n}^{1}\right)+\delta E\left\{\widetilde{U}\left(x_{1}^{2}, \ldots, x_{m}^{2}\right)\right\}
$$

To understand this utility, it is useful to contrast equation (2) with the equivalent in a traditional discounted utility model:

$$
\widetilde{U}\left(x_{1}^{1}, \ldots, x_{m}^{1}\right)+\widetilde{V}\left(x_{m+1}^{1}, \ldots, x_{n}^{1}\right)+\delta E\left\{\tilde{U}\left(x_{1}^{2}, \ldots, x_{m}^{2}\right)+\widetilde{V}\left(x_{m+1}^{2}, \ldots, x_{n}^{2}\right)\right\}
$$

The key difference with our formulation is that the term $\delta E\left\{\widetilde{V}\left(x_{m+1}^{2}, \ldots, x_{n}^{2}\right)\right\}$ is omitted. Thus for goods $i=1, . ., m$, the time 1 self uses the same utility function as the time 2 self and discounts the future by the same rate, $\delta$. However, the time 1 self places no weight on the utility derived from goods $i=m+1, \ldots, n$ in period 2 . Thus, goods $m+1, \ldots, n$, are the goods that the future self values but which today's self assigns zero weight. We will refer to these goods as "temptation goods".

Considerable simplification is possible if we make use of within period optimization. Choosing units so that all good prices are 1, we define the indirect utility functions

$$
U\left(x^{t}\right)=\max _{x_{1} \ldots x_{m}} \widetilde{U}\left(x_{1}^{1}, \ldots, x_{m}^{1}\right), \sum_{i=1}^{m} x_{i}^{t}=x^{t}, t=1,2
$$

\footnotetext{
${ }^{14}$ In the appendix we consider a model where goods have both temptation and nontemptation components and in this case the indices are merely a measure of the dollars spent on temptations.

${ }^{15}$ This setup can be obviously extended to more periods.
} 
and

$$
V\left(z^{t}\right)=\widetilde{V}\left(x_{m+1}^{2}, \ldots, x_{n}^{2}\right) \max _{x_{m+1} \ldots x_{n}}, \sum_{i=m+1}^{n} x_{i}^{t}=z^{t},
$$

The key insight is that the total amount spent on any subset of goods must be spent optimally within that subset, even when the consumer is actually deciding over a larger set. We can therefore write the above maximand in the compact form

$$
U\left(x^{1}\right)+V\left(z^{1}\right)+\delta E\left\{U\left(x^{2}\right)\right\} .
$$

For most of this paper, this is the utility function we will use. In essence, $x$ denotes the index of spending on non-temptation goods, while $z$ denotes the index of spending on temptation goods, much in the same way that $c$ denotes the spending on total consumption in traditional and hyperbolic discounting models. ${ }^{16}$ That both $U$ and $V$ should be increasing and concave follows from the corresponding assumptions about $\widetilde{U}$ and $\widetilde{V}$. Furthermore we will assume in everything we do that $U$ is at least three times differentiable everywhere. We refrain from making the corresponding assumption for the $V$ function to accommodate certain special cases.

An even more general formulation, which allows all goods to be desired both for their present and their future value, but with differing weights, is developed in the appendix. We show that it is possible to construct a $U(x)$ function and a $V(z)$ function such that the choices made under these preferences are exactly the same as those made under the original more complicated preferences. This ought to be intuitive: essentially, $x$ captures the part of the expenditure that aligns with what the forward-looking self wants, while $z$ is the part that is wasted from the forward-looking self's point of view, and it should not matter that the wasted expenditure takes the form of excess spending on goods that the forward-looking self also values (just not enough to justify that level of spending).

\subsection{Maximization}

Individuals maximize this utility subject to their budget constraints. In the first period they earn a deterministic "labor" income $y^{1}$. They can save a part of the income and invest it in some income generation function $f\left(w^{1}, \theta\right)$ where $w^{1}=y^{1}-x^{1}-z^{1}$ is the amount saved and $\theta$ is some random shock and $f(\cdot, \cdot)$ is the future income generated. We call this an income generation function (rather than a production technology) because we want to allow for the possibility that the person may borrow or lend and may invest all or part of the money in a production technology. Moreover he may or may not be constrained in terms of how much he can borrow or lend (and at what rates). It is easily checked that an $f(\cdot, \cdot)$ function that is increasing in $w^{1}$ accommodates all these cases. We will assume, in addition, that $f(\cdot, \cdot)$ is differentiable and concave in $w^{1}$ (but

\footnotetext{
${ }^{16}$ As a result, there are several underlying good-specific utility functions that can generate the index utility described in (3). Thus while the separable utility formulation in (2) generates it, other more complicated utility functions can also give rise to it.
} 
not necessarily strictly concave). This rules out poverty traps that arise from non-convexities in production (as in Galor-Zeira (1993)) or in the credit supply function (as in Banerjee-Newman (1994)).

In the second period, the person also gets a potentially uncertain "labor" income $y^{2}\left(\theta^{\prime}\right)$. We assume that $\theta$ and $\theta^{\prime}$ are independent random variables and that $\theta^{\prime}$ is realized in the second period before consumption decisions are taken.

As defined above, maximizing $U\left(x^{2}\right)+V\left(z^{2}\right)$ subject to a budget constraint $x^{2}+z^{2}=c^{2}$, and the conditions $\left(x^{2} \geq 0, z^{2} \geq 0\right)$ gives us functions $x^{2}\left(c^{2}\right)$ and $z^{2}\left(c^{2}\right)$. Under the standard assumption that both $U$ and $V$ are strictly concave, $x^{2}\left(c^{2}\right)$ and $z^{2}\left(c^{2}\right)$ will be non-decreasing in $c^{2}$. If $V$ is also differentiable (in addition to $U$ being differentiable), then $x^{2}\left(c^{2}\right)$ and $z^{2}\left(c^{2}\right)$ will be differentiable and strictly increasing everywhere except perhaps where the non-negativity constraint binds. Using the fact that $c^{2}=f\left(w^{1}, \theta\right)+y^{2}\left(\theta^{\prime}\right)$, we can write this as $x^{2}\left(f\left(w^{1}, \theta\right)+y^{2}\left(\theta^{\prime}\right)\right)$. Also for future use, define $z^{2}\left(x^{2}\right)$ to be the function that is defined by the first order condition for maximizing $U\left(x^{2}\right)+V\left(z^{2}\right)$ subject to a budget constraint $x^{2}+z^{2}=c^{2}$, i.e. by the equation $V^{\prime}\left(z^{2}\right)=U^{\prime}\left(x^{2}\right)$, and define $W(c)$ to be the indirect utility function defined by maximizing $U(x)+V(z)$ subject to a budget constraint $x+z=c$, and the conditions $(x \geq 0, z \geq 0)$. Since both $U$ and $V$ are increasing and strictly concave, so is $W(c)$.

The decision-maker in the first period is assumed to be sophisticated and therefore takes this function into account in making his first period choices. We assume that in the first period he gets an income/endowment $y^{1}$.

Therefore in the first period, the decision problem is to maximize

$$
U\left(x^{1}\right)+V\left(z^{1}\right)+\delta E_{\theta, \theta^{\prime}}\left\{U\left(x^{2}\left(f\left(w^{1}, \theta\right)+y^{2}\left(\theta^{\prime}\right)\right)\right)\right\}
$$

subject to

$$
w^{1}=y^{1}-x^{1}-z^{1}
$$

and

$$
x^{1} \geq 0, z^{1} \geq 0 .
$$

\subsection{First order conditions}

If an interior optimum exists and $\frac{d x^{2}\left(f\left(w^{1}, \theta\right)\right)}{d f\left(w^{1}, \theta\right)}$ and $\frac{d V\left(z^{1}\right)}{d z^{1}}$ exist at the optimum, then the following conditions must hold.

$$
\begin{aligned}
\lambda= & \frac{d U\left(x^{1}\right)}{d x^{1}} \\
\lambda= & \frac{d V\left(z^{1}\right)}{d z^{1}} \\
\lambda= & \delta E_{\theta, \theta^{\prime}}\left\{\frac{d U\left(x^{2}\left(f\left(w^{1}, \theta\right)+y^{2}\left(\theta^{\prime}\right)\right)\right)}{d x^{2}}\right. \\
& \left.\times \frac{d x^{2}\left(f\left(w^{1}, \theta\right)+y^{2}\left(\theta^{\prime}\right)\right)}{d f\left(w^{1}, \theta\right)} \frac{d f\left(w^{1}, \theta\right)}{d w^{1}}\right\} \\
w^{2}= & f\left(w^{1}, \theta\right)+y^{1}-x^{1}-z^{1}
\end{aligned}
$$


When the differentiability condition fails something similar holds with appropriately defined left-hand and right-hand derivatives.

These conditions can be rewritten in the more compact form:

$$
\begin{aligned}
\frac{d U\left(x^{1}\right)}{d x^{1}} & =\frac{d V\left(z^{1}\right)}{d z^{1}} \\
\delta E_{\theta, \theta^{\prime}}\left\{\frac{d U\left(x^{2}\left(c^{2}\right)\right)}{d x^{2}} \frac{d f\left(w^{1}, \theta\right)}{d w^{1}} \frac{d x^{2}\left(c^{2}\right)}{d c^{2}}\right\} & =\frac{d U\left(x^{1}\right)}{d x^{1}}
\end{aligned}
$$

\subsection{The Modified Euler Equation}

The condition

$$
\delta E_{\theta, \theta^{\prime}}\left\{\frac{d U\left(x^{2}\left(c^{2}\left(\theta, \theta^{\prime}\right)\right)\right.}{d x^{2}} \frac{d f\left(w^{1}, \theta\right)}{d w^{1}} \frac{d x^{2}\left(c^{2}\left(\theta, \theta^{\prime}\right)\right)}{d c^{2}}\right\}=\frac{d U\left(x^{1}\right)}{d x^{1}}
$$

where $c^{2}\left(\theta, \theta^{\prime}\right)=f\left(w^{1}, \theta\right)+y^{2}\left(\theta^{\prime}\right)$ ought to be reminiscent of the standard Euler equation in dynamic consumer maximization problems. Indeed, the only difference comes from the presence of the term $\frac{d x^{2}\left(c^{2}\right)}{d c^{2}}$ : In our setting the standard Euler equation would take the form

$$
\delta E_{\theta, \theta^{\prime}}\left\{\frac{d U\left(x^{2}\left(c^{2}\left(\theta, \theta^{\prime}\right)\right)\right)}{d x^{2}} \frac{d f\left(w^{1}, \theta\right)}{d w^{1}}\right\}=\frac{d U\left(x^{1}\right)}{d x^{1}} .
$$

The difference comes from the fact that there is some "dropped utility"—only part of the total expenditure on period 2 goods is valued by the period 1 self. Since $\frac{d U\left(x^{2}\left(c^{2}\left(\theta, \theta^{\prime}\right)\right)\right)}{d x^{2}}$ and $\frac{d f\left(w^{1}, \theta\right)}{d w^{1}}$ are always non-negative and $\frac{d x^{2}\left(c^{2}\right)}{d c^{2}} \leq 1$, this has the immediate implication that an observer who uses the modified Euler equation to estimate the decision-maker's discount factor as if it was the standard Euler equation (i.e. proxying it by the ratio $\widehat{\delta}=\frac{\frac{d U\left(x^{1}\right)}{d x^{1}}}{E_{\theta, \theta^{\prime}}\left\{\frac{d U\left(x^{2}\left(c^{2}\left(\theta, \theta^{\prime}\right)\right)\right)}{d x^{2}} \frac{d f\left(w^{1}, \theta\right)}{d w^{1}}\right\}}$ ), would think that the person is more impatient than he actually is $(\hat{\delta} \leq \delta)$. Moreover, it does not matter whether he uses an $x$ or a $z$ good to estimate the discount factor since, from the within period maximization $\frac{d U\left(x^{2}\left(c^{2}\left(\theta, \theta^{\prime}\right)\right)\right)}{d x^{2}}=$ $\frac{d V\left(z^{2}\left(c^{2}\left(\theta, \theta^{\prime}\right)\right)\right)}{d z^{2}}$ and $\frac{d U\left(x^{1}\right)}{d x^{1}}=\frac{d V\left(x^{1}\right)}{d x^{1}}$

In essence, the tempted consumer faces a temptation tax: he knows that future resources will be wasted on consumption that he does not care aboutonly a fraction $\frac{d x^{2}\left(c^{2}\right)}{d c^{2}}$ of the marginal dollar that he pushes into the future will be spent exactly as he wants. Sophistication about his own susceptibility to temptations then leads him to incorporate this tax on spending now and in particular, pushes him to be less forward-looking than he would be under full commitment. ${ }^{17}$

\footnotetext{
${ }^{17}$ If people were entirely naive about their temptations, many of the effects we emphasize here would not go through, though it is possible that the mistakes that naive decision makers make would sometimes have similar consequences. However our reading of the evidence is that consumers are at least partially sophisticated about their self control problems-for one they demand commitment devices. Indeed we believe most of our results would go through in
} 
While our two period framework makes the derivation of the Modified Euler Equation easier, the basic insight behind it is very general, and it can be shown that the T period version of our model, where in each period $s$ the consumer maximizes

$$
\sum_{t=s}^{T} \delta^{t-s} U\left(x^{t}\right)+V\left(z^{s}\right)
$$

subject to an intertemporal budget constraint similar to the one above, generates a necessary condition

$$
\delta E_{\theta, \theta^{\prime}}\left\{\frac{d U\left(x^{s+1}\left(c^{s+1}\right)\right)}{d x^{s+1}} \frac{d f\left(w^{s}, \theta\right)}{d w^{s}} \frac{d x^{s+1}\left(c^{s+1}\right)}{d c^{s+1}}\right\}=\frac{d U\left(x^{s}\right)}{d x^{s}},
$$

which is of course exactly the period $s$ version of the Modified Euler Equation. ${ }^{18}$

\section{Implications of the Modified Euler Equation}

The focus of this paper, as we say in the introduction, is on the implications of the declining temptations. However some of the broader implications of the Modified Euler equation are interesting in themselves, even before we introduce ideas relating to the shape of temptations and are this subject of this short section. Some of the intuitions we develop in this section, like those on durables, can be obtained, albeit perhaps less straightforwardly, from other models of selfcontrol problems. Others, like the discussion of "sin" taxes, is more unique to our framework.

\subsection{Demand for durables}

One implication of the self-control problem that is at the heart of our paper is that there may be some willingness to pay extra for illiquid durables. To see this, let's return to our original framework where there were multiple $x$ goods, each with an associated separable utility function. Assume now that there are two $x$ goods, $x_{1}$, which is non-durable and $x_{2}$, which represents a durable. The utility from $x$ is $u\left(x_{1}\right)$, increasing and concave. On the other hand assume that each unit of the durable purchased at time 1 pays $u_{d}$ units of additively separable $x$ utility in both periods 1 and 2 (constant marginal utility). In this case, an individual would be willing to pay up to $\frac{u_{d}}{u^{\prime}\left(x_{1}\right)}(1+\delta)$ in $x_{1}$ terms for this one unit; because it is committed $x$ consumption, it is discounted at rate $\delta$. On the other hand, he will make his savings decision based on a discount rate $\delta\left(1-z^{\prime}\left(c_{t}\right)\right)$. In other words, people appear to be more patient when we try to infer their patience from their purchases of durables than if we focus on their

somewhat modified versions if people were partially sophisticated in the sense that they have moments of lucidity when they see their self-control problems clearly and try to act on them. Examining these conjectures about partially sophisticated consumers analytically is left for future work.

${ }^{18}$ Proof available from the authors. The only important caveats have to do with the differentiability of the $x^{S}\left(c^{s}\right)$ function. 
generic savings decisions. In other words, people who seem too impatient to save even at high interest rates may still invest in consumption durables. The logic is simple: income is taxed by temptations, consumer durables provide an implicit commitment to $x$ consumption. ${ }^{19}$

\subsection{Demand for commitment}

Empirical evidence suggests that individuals may be interested explicitly in commitment devices. Ashraf, Karlan, and Yin (2004) provide a very nice illustration of this. They show that individuals who already have bank accounts take up and utilize a second "SEED" account whose primary advantage is illiquidity: individuals cannot withdraw deposits at will but can only do so when a (personally set) predetermined date or target amount is reached.

Demand for commitment savings accounts is a natural consequence of selfcontrol problems. Understanding the exact structure of this account however, requires an additional analytical step. In our model with constant temptations and a concave production technology, the ideal commitment device is one which provides maximal consumption smoothing. On the other hand the SEED accounts only permit withdrawals either when the amount in the account reaches a certain level or after a certain fixed date. In particular $70 \%$ of savers set date-based goals and pick dates like Christmas, someone's birthday or graduation. The most obvious way to make this consistent with consumption smoothing within our model is to assume that these are times when the value of non-temptation consumption $\left(\frac{U_{t}^{\prime}(x)}{V_{t}^{\prime}(z)}\right)$ is particularly large, which would imply, interestingly, that spending on festive occasions and "parties" is not temptation spending.

Amount-based goals, on the other hand, are naturally understood as an implication of the declining temptation assumption that we will introduce in the next section: To make sense of this case, we need to assume that there is relatively less temptation when the amount being spent is larger. Absent such an assumption, it is unclear why individuals would value transforming small amounts of cash into a large amount. Relatedly there is now a literature that argues that ROSCA's should be interpreted as a way to commit to save (Gugerty (2007) and Basu (2008)). This interpretation makes sense once again only with declining temptations.

\subsection{The effect of "sin" taxes}

As we observed, the key element that distinguishes this approach from the standard Euler Equation based approach to savings is captured by the term $\frac{d x^{2}\left(c^{2}\right)}{d c^{2}}$. A lower value of $\frac{d x^{2}\left(c^{2}\right)}{d c^{2}}$ corresponds to a bigger wedge between what the period 1 self wants and what the period 2 self will choose and therefore less savings.

\footnotetext{
${ }^{19}$ Note that this relies on our assumption that consumer durables provide additively separable utility. To the extent that durables provide utility that can be substituted for by future consumption choices, they would provide less commitment value and be demanded less.
} 
In this environment, suppose the government announces a tax on goods like cigarettes and alcohol, which is what is typically called a "sin" tax, and assume that these are also temptation goods as we have defined them (i.e. $z$ goods). What is the effect of such a tax on $\frac{d x^{2}\left(c^{2}\right)}{d c^{2}}$ and hence on savings, etc.?

To introduce the idea of a tax, let the price of $z$ goods in terms of $x$ goods be denoted by $p$. However since the price of $x$ goods is still "one" in both periods, the Modified Euler Equation is unaffected by this change and the effective discount factor is still determined by $\frac{d x^{2}\left(c^{2}\right)}{d c^{2}}$. To study the effect of a "sin" tax we want to know how an increase in $p$ in period 2 , affects $\frac{d x^{2}\left(c^{2}\right)}{d c^{2}}$.

To get at this, observe that the within second period budget constraint should now be written as $x^{2}+p z^{2}=c^{2}$. As a result, the allocation of $c^{2}$ between $x^{2}$ and $z^{2}$, will be determined by the condition

$$
p \frac{d U\left(x^{2}\right)}{d x^{2}}=\frac{d V\left(z^{2}\right)}{d z^{2}} .
$$

Differentiating this condition with respect to $c^{2}$, gives us:

$$
p U^{\prime \prime}\left(x^{2}\right) \frac{d x^{2}}{d c^{2}}=V^{\prime \prime}\left(z^{2}\right) \frac{d z^{2}}{d c^{2}}
$$

where $U^{\prime \prime}$ and $V^{\prime \prime}$ are the second derivatives of $U$ and $V$, and from the budget constraint we have that

$$
\frac{d x^{2}}{d c^{2}}+p \frac{d z^{2}}{d c^{2}}=1
$$

Solving these two together we get

$$
\frac{d x^{2}}{d c^{2}}+p^{2} \frac{U^{\prime \prime}\left(x^{2}\right)}{V^{\prime \prime}\left(z^{2}\right)} \frac{d x^{2}}{d c^{2}}=1
$$

which tell us that

$$
\frac{d x^{2}}{d c^{2}}=\frac{1}{1+p^{2} \frac{U^{\prime \prime}\left(x^{2}\right)}{V^{\prime \prime}\left(z^{2}\right)}}=\frac{1}{1+\frac{R_{U}}{R_{V}} \frac{p U^{\prime}\left(x^{2}\right)}{V^{\prime}\left(z^{2}\right)} \frac{p z^{2}}{x^{2}}}
$$

where $R_{U}$ and $R_{V}$ are the coefficients of relative risk-aversion corresponding to $U$ and $V$ at $x^{2}$ and $z^{2}$. Since $\frac{p U^{\prime}\left(x^{2}\right)}{V^{\prime}\left(z^{2}\right)}=1$, and $x^{2}=c^{2}-p z^{2}$ this simplifies to

$$
\frac{d x^{2}}{d c^{2}}=\frac{1}{1+\frac{R_{U}}{R_{V}} \frac{p z^{2}}{c^{2}-p z^{2}}} .
$$

Now assume that both $U$ and $V$ represent CRRA utility functions, though the coefficients of risk aversion do not have to be the same. Then the only place $p$ enters the expression for $\frac{d x^{2}}{d c^{2}}$ is through the term $\frac{p z}{x}$. It follows that a sin tax (which raises $p$ ) will reduce savings in this model as long as the demand for $z^{2}$ is less than unit elastic (so that $p z^{2}$ goes up when $p$ goes up). 
It has long been argued that "sin" taxes tend to be regressive. Here we suggest that they may also increase the level of present bias in people's choices and therefore possibly also affect savings behavior. The key insight is that sin taxes in this model have two effects. On the one hand they can reduce the amount spent on the temptation good. This makes sense if the temptation good has intrinsic ill effects-such as long run health consequences-something we do not have in our model. On the other hand they can also increase temptation good's share of expenditure and thereby generate effects on savings.

\section{The Shape of Temptation}

The key new idea in our framework is that temptation might have a specific shape. This shape of the temptation is captured by the shape of the $z(c)$ (or $x(c))$ function. The next result shows that for any given $U(x)$ function, the $z(c)$ function can in principle take any shape that we happen to pick for it, as long as it is increasing, non-negative and $z(c) \leq c$.

Proposition 1 Assume that the $U$ function is known and fixed. Let $z(c)$ and $x(c)$ be a pair of non-negative valued, strictly increasing functions defined on $c \in$ $[0, C]$ for some $C>0$, such that $z(c)+x(c)=c$. Then there exists an increasing, differentiable and strictly concave function $V$ defined on $[0, z(c)]$ such that the assumed $z(c)$ and $x(c)$ functions are the result of maximizing $U(x)+V(z)$ subject to a budget constraint $x+z=c$, and the conditions $(x \geq 0, z \geq 0)$

Proof. Define the function $g(z)=x(h(z))$ where the function $h(z)$ is the inverse of the function $z(c)$, which exists because of the strict monotonicity of $z$. Then define

$$
V(z)=\int_{0}^{z} U^{\prime}(g(y)) d y
$$

Clearly $V^{\prime}(z)=U^{\prime}(g(z))>0$. It is concave because when $z$ increases $g(z)$ increases and $U^{\prime}(g(z))$ decreases.

Note that we did not require that $z(c)$ be differentiable, and for that reason, $V$ may not be twice differentiable.

With this result in hand, the rest of the paper studies the implication of different shapes for the $z(c)$ function in the model of consumption and savings introduced above. The key distinction, it turns out, is between $z^{\prime}(c)$ decreasing and $z^{\prime}(c)$ constant or more generally, non-decreasing. Constant $z^{\prime}(c)$ means that irrespective of income, individuals face the same tax. Since $z(0)=0$, this means that the availability (and utility) of temptation goods scales linearly with the consumption bundle. Decreasing $z^{\prime}(c)$ on the other hand means that as individuals consume more, temptations are a smaller fraction of consumption: $\frac{z(c)}{c}$ is declining with income. 


\subsection{Declining and non-declining temptations}

The key advantage of our framework is precisely its ability to easily capture temptations that vary with the level of income and in particular, the declining temptation case. In the Modified Euler Equation (5), the temptation tax is embodied by $\frac{d z^{2}\left(c^{2}\right)}{d c^{2}}=1-\frac{d x^{2}\left(c^{2}\right)}{d c^{2}}$ : for every dollar spent, $\frac{d z^{2}\left(c^{2}\right)}{d c^{2}}$ is the tax imposed by the period 2 self. Whether the tax declines with overall consumption therefore depends on whether $\frac{d z^{2}\left(c^{2}\right)}{d c^{2}}$ decreases or increases with income. Specifically if $\frac{d z^{2}\left(c^{2}\right)}{d c^{2}}$ decreases with total consumption, that is to say if $z^{2}\left(c^{2}\right)$ is concave, the impact of the tax decreases as consumption rises. Put differently, this offers an intuitive way to model the idea that self control problems scale slower than incomes. In the rest of the paper we will contrast this case which we will call the diminishing temptation case (DTC) with the alternative case where temptation does not decline $\left(\frac{d z^{2}\left(c^{2}\right)}{d c^{2}}\right.$ is constant or increasing with $\left.c^{2}\right)$ which we will call the non-diminishing temptation case (NDTC). Note that NDTC includes the case where $z^{2}\left(c^{2}\right)=0$, i.e. there are no temptations. Obviously there are many other cases where $z^{2}$ is neither convex nor concave everywhere which fall into neither of these categories. Our results would then apply for local changes in incomes/consumption but not otherwise.

What does it mean for $z^{2}\left(c^{2}\right)$ to be concave? The following result offers an alternative and perhaps more intuitive characterization:

Proposition 2 Assuming that $V$ and $U$ are three times differentiable everywhere and $z^{2}\left(c^{2}\right)$ is twice differentiable everywhere. Then $z^{2}\left(c^{2}\right)$ is strictly (weakly) concave everywhere if and only if $\widetilde{V}\left(x^{2}\right)=V\left(z^{2}\left(x^{2}\right)\right)$ is a strict (weak) concave transform of $U\left(x^{2}\right)$.

Proof. In appendix.

In other words our condition is equivalent to assuming that $V$ is more concave than $U$ in this specific sense. So, for example, if both of them are CRRA, then we are asking the coefficient of relative "risk-aversion" on $V$ to be greater than that on $U$.

Why should we believe that $z^{2}\left(c^{2}\right)$ is concave or equivalently $V$ is more concave than $U$ ? It is probably worth saying to start out that to simplify the exposition we are ignoring the one obvious case where this assumption probably fails-that is for the people who are at the margin of starvation. For those people it is plausible that the first units of an $x$ good like nutritious food are probably much more valuable than anything else, and for that reason it is natural to think of $z^{2}\left(c^{2}\right)$ being convex around zero consumption. By ignoring this possibility we are focusing on people who are slightly above the starvation threshold. For such people there are a number of arguments for why $z^{2}\left(c^{2}\right)$ should be concave. ${ }^{20}$

The first is based on the idea that most temptations are essentially visceral, reflecting desires that are rooted in our physiology (things like the the desire

\footnotetext{
${ }^{20}$ Which amounts to saying that the overall $z^{2}\left(c^{2}\right)$ function is probably S-shaped, with a point of inflexion near zero.
} 
for sex, the craving for sweets and the love of fatty foods), and for that reason, relatively insensitive to the variety and range of quality that modern market economies offer (this should be true, for example, if the relevant physiological structures evolved in a world where the set of consumption choices was quite limited). As a result it is hard to spend a lot of money on temptation goods without hitting satiation.

Second, a lot of the goods that people look forward to owning tend to be indivisible and therefore relatively expensive (televisions, means of transportation, a house). In other words, a lot of the most attractive $x$ goods are only available to those who can spend enough on them, whereas $z$ goods are usually divisible and therefore available to everyone. Therefore it is possible to spend much larger amounts on $x$ and still not reach satiation. ${ }^{21}$

Third, for the family decision-making example suggested above, it may be easier for a rich person to say no to a relative who wants a few hundred dollars for starting a new business, than for a poor person to refuse one who wants just a couple of dollars for a meal. ${ }^{22}$

Finally one can make the case that for most really expensive goods, like a sports car or a house, are not really available for an impulse purchase in the same sense in which a cup of sugary tea or a trinket is - there are always multiple options that need to be examined and weighed, and processes to go through (have someone check out the deed for the house, inspection) and all of that ensures that there is time for reflection and reconsideration. In other words, there is a stage in the purchase of a house or a car that involves paying a cost now (talk to lawyers, arrange credit) for a future benefit. In this sense they have to be in part $x$ goods.

In any case, whether this assumption holds is an empirical question. One tantalizing piece of evidence comes from Deaton and Subramanian's (1996) work on food expenditures. They show that in rural Maharashtra, the poorest decile of rural households spends $12.2 \%$ of their total expenditures on sugar, oils and fats. These are goods that could plausibly be thought to have some temptation component $^{23}$ (or at very the least to have more temptation value than cereals or pulses). For the richest decile, who are also by no means rich, even by Indian standards, this number is $8.7 \%$. While there surely are other temptation goods,

\footnotetext{
${ }^{21}$ Note that this is not inconsistent with $U(\cdot)$ being concave. Formally we assume that there are a continuum of indivisible $x$ goods indexed by $k$, such that good $x_{k} \operatorname{costs} x(k)$ and generates utility $u(x(k))$. We then define $U(x)=\max _{k}\left\{u\left(x_{k}\right), x(k) \leq x\right)$ to be the utility from $x$ expenditures. It is easy to specify conditions under which $U(x)$ will be concave. Of course, our framework could be extended to the case where the $U(x)$ function is in fact non-convex (which would be the case if there only a few isolated goods that are worth buying) but our results do not rely on the non-convexity. Also see the discussion of non-convexities in the next section.

${ }^{22} \mathrm{It}$ is true that there is a countervailing force: The richer the person is, the more relatives probably descend on him, and even all his is willing to give them is a few pennies, they do add up. However the point when the list of everyone who can legitimately make a claim on him cannot take too long to be exhausted, and thereafter the fraction of the marginal dollar going to them will diminish.

${ }^{23}$ In Section 6 we return to the central issue of how one might be able to determine which goods are temptation goods.
} 
this declining fraction illustrates our core assumption. Another interesting category is leisure, which is plausibly, at least in part, a $z$ good: There is some evidence that leisure hours decrease with income (Banerjee and Duflo (2007)). For example, in rural Indonesia, those living at less than a $\$ 1$ a day work 34.6 hours a week while those living on 2 to 4 dollars a day work 40.8 hours. $^{24}$

There are two other ways to test the framework. First, in the next sections we present a set of direct and testable consequences of $z^{2}\left(c^{2}\right)$ being concave. Testing them is a way to jointly test our model and this assumption. A second approach, which we take up in Section 6 is more direct. We describe how, using household consumption data and a set of choice experiments, one could plausibly determine the set of goods that are relatively more tempting. Examining whether these goods are a decreasing share of the budgets of the rich allows us to directly test the assumption that $z^{2}\left(c^{2}\right)$ is concave.

\subsection{Relation to hyperbolic discounting}

There are two distinct ways to understand how this model is related to the hyperbolic discounting model. The first is to start with the hyperbolic discounting model and to extend it to the case of two goods. A simple model with two goods and good-specific hyperbolic discounting assumes that the first period self maximizes

$$
U\left(x^{1}\right)+\beta \delta U\left(x^{2}\right)+\beta \delta^{2} U\left(x^{3}\right)+V\left(z^{1}\right)+\beta^{\prime} \delta V\left(z^{2}\right)+\beta^{\prime} \delta^{2} V\left(z^{3}\right),
$$

while the second period self maximizes

$$
U\left(x^{2}\right)+\beta \delta U\left(x^{3}\right)+V\left(z^{2}\right)+\beta^{\prime} \delta V\left(z^{3}\right) .
$$

Notice that time inconsistency here comes from two sources: The conventional hyperbolic effect, captured by the fact that the weight that period 2 self puts on period 3's consumption $\left(\beta \delta\right.$ and $\left.\beta^{\prime} \delta\right)$ is less than the weight that period 1 would like him to place ( $\delta$ for both goods); but also a new effect, represented by the fact that while period 2 self places the same weight on $U\left(x^{2}\right)$ and $V\left(z^{2}\right)$, period 1 self puts unequal weights on them, since $\beta$ is not equal to $\beta^{\prime}{ }^{25}$ But that makes it obvious that to generate time inconsistent behavior we do not need the third period, since the new effect makes no reference to period 3 . Since we want to emphasize goods specific discount factors in any case, this offers us a convenient short-cut-we can drop the third period and analyze the problem in a two period setting. In addition, in the appendix we show that for specific $U$ and $V$ functions, with three or more periods, we can exactly recreate the horizon-specific discount factors of the hyperbolic model solely from good specific discount factors.

Another way to understand how our model relates to the hyperbolic model is to ask the reverse question. Suppose one did not explicitly model that some

\footnotetext{
${ }^{24}$ While these differences are large, they are obviously not large enough for hours differences alone to produce the income differences.

${ }^{25}$ There is a third effect, which is the equivalent of the second effect in period 3.
} 
goods are more tempting than others. Instead, suppose one asks directly in a standard hyperbolic model "What condition generates greater time inconsistency for the poor?" In other words, what is the analogue of the declining tax for the hyperbolic discounting model?

To answer this question we need a model with three periods, since the hyperbolic part only kicks in when there are more than two periods. Therefore let the decision maker maximize

$$
U\left(c_{1}\right)+\beta \delta U\left(c_{2}\right)+\beta \delta^{2} U\left(c_{3}\right)
$$

subject to the budget constraint

$$
c_{1}+c_{2}+c_{3}=w^{26}
$$

As is well-known (from Harris-Laibson (2001) for example), the optimal consumption path for this decision-maker is characterized by the following first order condition

$$
U^{\prime}\left(c_{1}\right)=\beta \delta U^{\prime}\left(c_{2}\right)\left[1-\beta c_{2}^{\prime}\left(w_{2}\right)\right]
$$

where $c_{2}\left(w_{2}\right)$ is defined by the second period decision maker's first order condition

$$
U^{\prime}\left(c_{2}\left(w_{2}\right)\right)=\beta \delta U^{\prime}\left(w_{2}-c_{2}\right)
$$

and $w_{2}=w-c_{1}$.

The equivalent of what we called the tax before is the term $1-\beta c_{2}^{\prime}\left(w_{2}\right)$. We are interested in the conditions under which $c_{2}^{\prime}\left(w_{2}\right)$ is decreasing in $w_{2}$. From the second period decision-maker's first order condition,

$$
c_{2}^{\prime}\left(w_{2}\right)=\frac{\beta \delta U^{\prime \prime}\left(c_{3}\right)}{U^{\prime \prime}\left(c_{2}\right)+\beta \delta U^{\prime \prime}\left(c_{3}\right)} .
$$

Differentiation again yields

$$
\begin{aligned}
& c_{2}^{\prime \prime}\left(w_{2}\right) \\
& =\frac{1}{\left[U^{\prime \prime}\left(c_{2}\right)+\beta \delta U^{\prime \prime}\left(c_{3}\right)\right]^{2}}\left\{\beta \delta U^{\prime \prime \prime}\left(c_{3}\right)\left(1-c_{2}^{\prime}\left(w_{2}\right)\right)\left[U^{\prime \prime}\left(c_{2}\right)+\beta \delta U^{\prime \prime}\left(c_{3}\right)\right]\right. \\
& \left.-\beta \delta U^{\prime \prime}\left(c_{3}\right)\left[U^{\prime \prime \prime}\left(c_{2}\right) c_{2}^{\prime}\left(w_{2}\right)+\beta \delta U^{\prime \prime \prime}\left(c_{3}\right)\left(1-c_{2}^{\prime}\left(w_{2}\right)\right)\right]\right\} \\
& =\frac{\beta \delta U^{\prime \prime \prime}\left(c_{3}\right)\left(1-c_{2}^{\prime}\left(w_{2}\right)\right) U^{\prime \prime}\left(c_{2}\right)-\beta \delta U^{\prime \prime}\left(c_{3}\right) U^{\prime \prime \prime}\left(c_{2}\right) c_{2}^{\prime}\left(w_{2}\right)}{\left[U^{\prime \prime}\left(c_{2}\right)+\beta \delta U^{\prime \prime}\left(c_{3}\right)\right]^{2}}
\end{aligned}
$$

It follows that, $c_{2}^{\prime \prime}\left(w_{2}\right)<0$, iff $\frac{U^{\prime \prime \prime}\left(c_{3}\right)}{\left[U^{\prime \prime}\left(c_{3}\right)\right]^{2}}<\frac{\beta \delta U^{\prime \prime \prime}\left(c_{2}\right)}{\left[U^{\prime \prime}\left(c_{2}\right)\right]^{2}}$. The hyperbolic model equivalent of $U$ utility being less concave than $V$ utility is a property regarding how $U^{\prime \prime \prime}(c)$ changes relative to the square of $U^{\prime \prime}(c)$. Not only is this condition harder to interpret, it is harder to imagine how one would empirically validate it. In the rest of the paper we therefore focus on good-specific temptations.

\footnotetext{
${ }^{26}$ In other words we assume that the gross interest rate is 1.
} 


\section{Implications of declining temptations}

\subsection{Attributions of Impatience}

A simple observation trivially follows from our key assumption. Recall that in subsection 2.4 we had defined $\widehat{\delta}$ to be the discount factor that an observer would (mistakenly) attribute to our decision-maker, if he assumes a model with no dropped utility. In the case where there is no uncertainty,

$$
\widehat{\delta}=\delta\left[1-\frac{d z^{2}}{d c^{2}}\right] .
$$

Since $z^{2}$ is assumed to be concave as a function of $c^{2}$, this tells us that those who are richer, in the sense of consuming more in the second period, will appear to be more patient to the observer despite the fact that everyone has the same $\delta$. As will be shown later, second period consumption is monotonic in first period total income, and hence this could also be stated in terms of first period income (and also in terms of second period income). ${ }^{27}$

This framework, therefore, suggests an intuitive re-interpretation of the common observation that the poor seem to be more myopic than the non-poor that goes back at least to Irving Fisher (1932). This is a direct consequence of declining temptations, which, it is worth emphasizing, does not say that the poor are more tempted. Indeed the amount spent on temptation goods over the lifetime is strictly increasing in initial wealth; it is just that it takes a smaller fraction of total consumption to satisfy one's temptations at high levels of consumption, which is why the same failures (giving in to temptations) have greater consequences when poor. ${ }^{28}$

\subsection{Chaining}

For simplicity, we have focused on the two-period case, but having two periods masks a magnification that happens when the horizon is longer. This magnification, which we refer to as chaining, is especially important for quantifying the importance of temptation. Here we add a third period to illustrate this chaining effect. The model extends to 3 periods in the most obvious way; in addition, to keep thing simple, we assume that the person starts with an endowment of $w_{1}$ and can only save at at the gross interest rate of 1 .

We solve through backward induction. The third period self simply maximizes $U\left(x_{3}\right)+V\left(z_{3}\right)$ subject to $x_{3}+z_{3}=w_{3}=w_{2}-c_{2}$. This defines $x_{3}\left(w_{3}\right)=$ $x_{3}\left(w_{2}-c_{2}\right)$. The second period self now maximizes $U\left(x_{2}\left(c_{2}\right)\right)+V\left(z_{2}\left(c_{2}\right)\right)+$ $\delta U\left(x_{3}\left(w_{2}-c_{2}\right)\right)$, which gives us $c_{2}\left(w_{2}\right)$. Given the solution to this problem, the first period decision maker maximizes

$$
U\left(x_{1}\left(c_{1}\right)\right)+V\left(z_{1}\left(c_{1}\right)\right)+\delta U\left(x_{2}\left(c_{2}\left(w_{1}-c_{1}\right)\right)+\delta^{2} U\left(x_{3}\left(w_{2}-c_{2}\left(w_{1}-c_{1}\right)\right)\right)\right.
$$

\footnotetext{
${ }^{27}$ We put it in terms of second period consumption because, as will emerge, first period consumption is not necessarily monotonic in first period wealth.

${ }^{28}$ Note that although we do not model it here, one could include a self-control technology here. In that language, we would say that the poor require greater self-control since they would need to resist giving into the same temptations more than the rich.
} 
In deciding how much to consumer, period 1 self trades off utility today from consumption $\left(U\left(x_{1}\left(c_{1}\right)\right)+V\left(z_{1}\left(c_{1}\right)\right)\right.$ and the future utility that savings would provide. Define $W_{u}(\cdot)$ to be this future utility:

$$
W_{u}\left(w_{1}-c_{1}\right)=U\left(x_{2}\left(c_{2}\left(w_{1}-c_{1}\right)\right)+\delta U\left(x_{3}\left(w_{2}-c_{2}\left(w_{1}-c_{1}\right)\right)\right)\right.
$$

The marginal benefit of savings is given by differentiation:

$$
\begin{aligned}
& W_{u}^{\prime}\left(w_{1}-c_{1}\right) \\
= & U^{\prime}\left(x_{2}\right) x_{2}^{\prime}\left(c_{2}\right) c_{2}^{\prime}\left(w_{1}-c_{1}\right) \\
& +\delta U^{\prime}\left(x_{3}\right) x_{3}^{\prime}\left(c_{3}\right)\left[1-c_{2}^{\prime}\left(w_{1}-c_{1}\right)\right] \\
= & U^{\prime}\left(x_{3}\right) x_{3}^{\prime}\left(c_{3}\right)- \\
& {\left[\delta U^{\prime}\left(x_{3}\right) x_{3}^{\prime}\left(c_{3}\right)-U^{\prime}\left(x_{2}\right) x_{2}^{\prime}\left(c_{2}\right)\right] c_{2}^{\prime}\left(w_{1}-c_{1}\right) }
\end{aligned}
$$

where $c_{3}=w_{2}-c_{2}\left(w_{1}-c_{1}\right)$.

But from the first order condition for the period 2 self's maximization,

$$
U^{\prime}\left(x_{2}\right)=\delta U^{\prime}\left(x_{3}\right) x_{3}^{\prime}\left(c_{3}\right)
$$

which means the above expression can be rewritten as

$$
\begin{aligned}
W_{u}^{\prime}\left(w_{1}-c_{1}\right)= & \delta U^{\prime}\left(x_{3}\right) x_{3}^{\prime}\left(c_{3}\right) \\
& -U^{\prime}\left(x_{2}\right)\left(1-x_{2}^{\prime}\left(c_{2}\right)\right) c_{2}^{\prime}\left(w_{1}-c_{1}\right)
\end{aligned}
$$

Compare this to the case where there is only one future period in the slightly artificial sense that the period 1 self controls $c_{2}$ (as well as $c_{1}$ ) but not $x_{2}$ or $x_{3}$. In this case, the reward to saving is given by the function

$$
W_{u}\left(w_{1}-c_{1}\right)=\max _{c_{2}} U\left(x_{2}\left(c_{2}\right)+\delta U\left(x_{3}\left(w_{2}-c_{2}\right)\right)\right.
$$

From the envelope theorem we have the reward for an extra dollar of saving in this case is

$$
W_{u}^{\prime}\left(w_{1}-c_{1}\right)=\delta U^{\prime}\left(x_{3}\right) x_{3}^{\prime}\left(c_{3}\right) .
$$

Comparing this expression with the previous one makes clear that the reward for saving is less in the case where the period 1 self faces two independent future decision-makers than in the case where he faces one.

This is the sense in which there is "chaining" of temptations: the period 1 self is more tempted in the three period case because he knows that the period 2 self is also tempted, and will "waste" some of the resources that reach him before they get to the period 3 self.

\subsection{Consumption smoothing}

One of the most robust predictions of the standard model of savings is that an increase in future earnings $\left(y^{2}\right)$ that leaves the return on investment unaffected will reduce today's savings and increase today's consumption $\left(c^{1}\right)$. This is the 
direct result of the desire for consumption smoothing, induced by diminishing marginal utility. An increase in future income generates a desire to spend more both today and tomorrow. In our model, however, this need not be the case because there is a natural countervailing force. Notice that as $y^{2}$ rises, $\frac{d x^{2}}{d c^{2}}$ goes up and as a result, the right-hand-side of the Modified Euler equation could potentially even go up: The increased spending by the future self on $x^{2}$ increases today's self's desire to transfer income to the future and may even outweigh the effect of diminishing marginal utility.

Proposition 3 Assume that second period income, $y^{2}$, is deterministic. Under $N D T C$, consumption today is increasing in future income: $\frac{d c^{1}}{d y^{2}}>0$. Under DTC this need not be the case i.e. we might observe $\frac{d c^{1}}{d y^{2}}<0$ over some range of $y^{2}$. Moreover we will only observe this pattern for people for whom $y^{1}$ and $y^{2}$ are sufficiently small.

Proof. Take the Modified Euler equation for this case

$$
\delta E_{\theta}\left\{\frac{d f\left(w^{1}, \theta\right)}{d w^{1}} \frac{d U\left(x^{2}\left(c^{2}(\theta)\right)\right)}{d x^{2}} \frac{d x^{2}\left(c^{2}(\theta)\right)}{d c^{2}}\right\}=U^{\prime}\left(x^{1}\right)
$$

where $c^{2}(\theta)=f\left(y^{1}-x^{1}-z^{1}, \theta\right)+y^{2}$. In the NDTC, for any value of $\theta$ an increase in $y^{2}$ keeping $c^{1}=x^{1}+z^{1}$ fixed, increases $x^{2}=c^{2}(\theta)$ and therefore depresses $U^{\prime}\left(x^{2}\left(c^{2}(\theta)\right)\right)$ for every realization of $\theta$. Moreover it either depresses $\frac{d x^{2}\left(c^{2}(\theta)\right)}{d c^{2}}$ or leaves it unchanged, for every realization of $\theta$. Since $\frac{d f\left(w^{1}, \theta\right)}{d w^{1}}$ is unchanged for each realization of $\theta$, the left hand side is now less than the right hand side. Therefore $x^{1}$ has to go up to restore equality, and since $U^{\prime}\left(x^{1}\right)=V^{\prime}\left(z^{1}\right), z^{1}$ must follow suit. Therefore a higher $y^{2}$ must be associated with a higher $c^{1}$.

In the DTC, i.e. where $\frac{d x^{2}\left(c^{2}(\theta)\right)}{d c^{2}}$ is increasing, the basic logic is very similar except that it is no longer obvious that the right hand side goes down. To see this, take this case where $U(x)=\log x$. In that case, the product

$$
\begin{aligned}
& \frac{d U\left(x^{2}\left(c^{2}(\theta)\right)\right)}{d x^{2}} \frac{d x^{2}\left(c^{2}(\theta)\right)}{d c^{2}} \\
= & \frac{1}{x^{2}\left(c^{2}(\theta)\right)} \frac{d x^{2}\left(c^{2}(\theta)\right)}{d c^{2}} .
\end{aligned}
$$

Whether $x^{1}$ goes up or goes down turns on whether $\frac{1}{x^{2}\left(c^{2}\right)} \frac{d x^{2}\left(c^{2}\right)}{d c^{2}}$ is increasing or decreasing as a function of $c^{2}$. A sufficient condition for this is that $x^{2}\left(c^{2}\right)$ is $\log$ convex for $c^{2} \leq \max _{\theta} f\left(y^{1}, \theta\right)+\bar{y}^{2}$, where $\bar{y}^{2}$ is the ceiling of the relevant range of $y^{2}$. It is easy to check that there are log-convex functions that are non-negative valued and satisfy $x^{2}\left(c^{2}\right) \leq c^{2}$ on any given finite range of $c^{2}$. Therefore from proposition 1 we can find a $V(z)$ function which makes $x^{2}\left(c^{2}\right)$ is log-convex. In such cases $c^{1}$ will be decreasing in $y^{2}$.

Finally it is clear from the argument above that in order for $c^{1}$ to be decreasing in $y^{2}, x^{2}\left(c^{2}\right)$ has to be sufficiently convex to outweigh the natural concavity of the utility function. However since $x^{2}\left(c^{2}\right)$ is bounded above by $c^{2}$, there is 
a limit to how convex $x^{2}\left(c^{2}\right)$ can be on a unbounded domain-for large enough values of $c^{2}, x^{2}\left(c^{2}\right)$ must be approximately linear. Therefore $c^{1}$ can only be decreasing in $y^{2}$ for sufficiently low values of $y^{1}$ and $y^{2}$ (since $c^{2}$ is increasing in $y^{1}$ and $\left.y^{2}\right)$.

This is a striking conclusion. It tells us that those who are sufficiently poor might actually react to the prospect of future income growth by beginning to save more. Conversely savings may actually be lower in exactly those times when cash will be needed the most in the future: faced with falling future incomes, people may boost consumption. This offers a possible interpretation of the idea that aspirations matter (Ray (2002) makes the case that economists need to take aspirations more seriously).

This result can be understood from a different angle, one that offers an intuition that helps us understand other results below. Consider an individual with a time-consistent utility function $u\left(c^{1}\right)+\delta u\left(c^{2}\right)$. Suppose however, that instead of a investment technology that earns $f\left(w^{1}\right)$, he has only access to a technology that pays a return $f\left(w^{1}\right) x^{\prime}\left(f\left(w^{1}\right)+y^{2}\right)$. Consider now the impact of an increase in $y^{2}$. There is the usual consumption smoothing motive that encourages an increase in $c^{1}$. But here, however, there's an additional motive: the investment technology becomes more attractive: If the latter motive is strong enough, we might see the opposite of consumption smoothing.

Note that this is a result we could also get from a model where there are no self-control problems but there are non-convexities in consumption: It comes from the fact that from the point of view period 1 self, the marginal utility of a dollar tomorrow goes up when he spends more tomorrow. On the other hand, when there are self-control problems it can happen absent any non-convexities in consumption, The same applies to the next two set of results-on poverty traps, precautionary savings and investment, which are essentially applications of the logic developed in this section-but not the results in the last two sub-sections, which are on the supply and demand for credit, where the self-control plays an essential role.

\subsection{Poverty Traps}

This link between future income and savings has implications for first period income as well. First period income determines how much can be left for future selves. But since the savings invested for future consumption at time $1\left(w^{1}\right)$ and income at time $2\left(y^{2}\right)$ have similar effects, it is clear that a rise in $y^{1}$ could, in principle, have the same effect as an increase in $y^{2}$. If individuals start out with more income/wealth (which in this model are the same thing), they will be able to leave more to future selves. But this potentially creates a feedback effect: more wealth for time 2 means that $x^{\prime}$ is higher in that period, which creates an even greater desire to leave wealth to time 2 . This feedback effect can be the source of a poverty trap:

Proposition 4 Assume that there are no shocks i.e. that both $\theta_{1}$ and $\theta_{2}$ are constants. Then as long as we are in NTDC, $c^{2}$ will be a continuous function 
of $y^{1}$. On the other hand in DTC, there may exist a $\bar{y}^{1}, 0<\bar{y}^{1}<\infty$ such that $c^{2}$ jumps discontinuously upward at $\bar{y}^{1}$.

Before we come to the main result, it is useful to observe that $c^{2}$ is always monotonic increasing with respect to $y^{1}$ and therefore the fact that $c^{2}$ jumps upwards if it jumps is automatic.

Lemma $5 c^{2}$ is monotonically increasing as a function of $y^{1}$.

Proof. (of Lemma 5) To see this, suppose to the contrary that there exists $y_{0}^{1}$ and $y_{1}^{1}$ such that $c^{2}\left(y_{0}^{1}\right)>c^{2}\left(y_{1}^{1}\right)$ but $y_{0}^{1}<y_{1}^{1}$. Let the values $c^{1}$ corresponding to this strategy be $c^{1}\left(y_{0}^{1}\right)$ and $c^{1}\left(y_{1}^{1}\right)$. Clearly $c^{1}\left(y_{0}^{1}\right)<c^{1}\left(y_{1}^{1}\right)$. Now consider an alternative consumption strategy for the person at $y_{0}^{1}$ where he consumes $c^{2}\left(y_{1}^{1}\right)$ in the second period and sets $\widetilde{c}_{0}^{1}=c^{1}\left(y_{0}^{1}\right)+\frac{c^{2}\left(y_{0}^{1}\right)-c^{2}\left(y_{1}^{1}\right)}{R}$. This must be dominated by what he actually chooses which implies that

$$
\begin{aligned}
& W\left(\widetilde{c}_{0}^{1}\right)-W\left(c^{1}\left(y_{0}^{1}\right)\right) \\
\leq & \delta U\left(x^{2}\left(c^{2}\left(y_{0}^{1}\right)\right)\right)-\delta U\left(x^{2}\left(c^{2}\left(y_{1}^{1}\right)\right)\right)
\end{aligned}
$$

Where

$$
W(c)=\max _{x} U(x)+V(c-x)
$$

On the other hand, the person at $y_{1}^{1}$ clearly prefers the pair $\left\{c^{1}\left(y_{1}^{1}\right), c^{2}\left(y_{1}^{1}\right)\right\}$ to the alternative of consuming $\widetilde{c}_{1}^{1}=c^{1}\left(y_{1}^{1}\right)-\frac{c^{2}\left(y_{0}^{1}\right)-c^{2}\left(y_{1}^{1}\right)}{R}$ in the first period and $c^{2}\left(y_{0}^{1}\right)$ in the second. Therefore

$$
\begin{aligned}
& W\left(c^{1}\left(y_{1}^{1}\right)\right)-W\left(\widetilde{c}_{1}^{1}\right) \\
\geq & \delta U\left(x^{2}\left(c^{2}\left(y_{0}^{1}\right)\right)\right)-\delta U\left(x^{2}\left(c^{2}\left(y_{1}^{1}\right)\right)\right) \\
\geq & W\left(\widetilde{c}_{0}^{1}\right)-W\left(c^{1}\left(y_{0}^{1}\right)\right)
\end{aligned}
$$

However since $\widetilde{c}_{0}^{1}-c^{1}\left(y_{0}^{1}\right)=c^{1}\left(y_{1}^{1}\right)-\widetilde{c}_{1}^{1}=\frac{c^{2}\left(y_{0}^{1}\right)-c^{2}\left(y_{1}^{1}\right)}{R}$ and $c^{1}\left(y_{0}^{1}\right)<c^{1}\left(y_{1}^{1}\right)$, this contradicts the strict concavity of $W$.

Proof. (of Proposition 4) Consider the maximization problem:

$$
U\left(x^{1}\right)+V\left(z^{1}\right)+\delta U\left(x^{2}\left(f\left(y^{1}-x^{1}-z^{1}\right)+y^{2}\right)\right)
$$

subject to

$$
x^{1} \geq 0, z^{1} \geq 0 .
$$

As long as we are in NDTC, so that $x^{2}\left(c^{2}\right)$ is weakly concave, the strict concavity of $U(\cdot)$ and the weak concavity of $f(\cdot)$ (and the fact that these are all strictly increasing functions) guarantees that $U\left(x^{2}\left(f\left(y^{1}-x^{1}-z^{1}\right)+y^{2}\right)\right)$ is a strictly convex (and decreasing) function of $x^{1}$ and $z^{1} \cdot U\left(x^{1}\right)$ and $V\left(z^{1}\right)$ are also strictly concave. These conditions together guarantee that we have a strictly convex maximization problem, which tells us that the maximizers, $x^{1}$ and $z^{1}$, are always unique and vary continuously as a function of the parameters of the problem, $y^{1}$ and $y^{2}$. Hence the result. 
In DTC, on the other hand, this may not be true. To simplify the construction assume that $f\left(y^{1}-x^{1}-z^{1}\right)=R\left(y^{1}-x^{1}-z^{1}\right)$, with $\delta R>1$. Also set $y^{2}=0$.

The way we will analyze this problem is by looking at how $c^{2}-c^{1}$ behaves as a function of $y^{1}$. Clearly if $c^{2}$ is a continuous function of $y^{1}$, so is $c^{1}$ and $c^{2}-c^{1}$.

Choose an $x^{2}\left(c^{2}\right)$ function which is convex (corresponding to the fact that we are in DTC) such that there exists a $c^{*}, \infty>c^{*}>0$, with $\delta R \frac{d x^{2}\left(c^{*}\right)}{d c^{2}}=1$. Because $\delta R \frac{d x^{2}\left(c^{*}\right)}{d c^{2}}=1$, if $c^{2}\left(y^{1}\right)=c^{*}$, then $c^{1}\left(y^{1}\right)=c^{2}\left(y^{1}\right)=c^{*}$. However for this to be true, $x^{1}=x^{2}\left(c^{*}\right)$, must satisfy the second order condition

$$
U^{\prime \prime}\left(x^{1}\right)+\delta R^{2} U^{\prime \prime}\left(x^{2}\left(c^{*}\right)\right)\left[\frac{d x^{2}\left(c^{*}\right)}{d c^{2}}\right]^{2}+\delta R U^{\prime}\left(x^{1}\right) \frac{d^{2} x^{2}\left(c^{*}\right)}{d\left(c^{2}\right)^{2}} \leq 0
$$

Since $x^{1}=x^{2}\left(c^{*}\right)$ and $\delta R \frac{d x^{2}\left(c^{*}\right)}{d c^{2}}=1$, this expression can be rewritten as

$$
\begin{aligned}
0 \geq & \delta \frac{U^{\prime}\left(x^{2}\left(c^{*}\right)\right)}{x^{2}\left(c^{*}\right)}\left[\left\{x^{2}\left(c^{*}\right) \frac{U^{\prime \prime}\left(x^{2}\left(c^{*}\right)\right)}{U^{\prime}\left(x^{2}\left(c^{*}\right)\right)}\right\}(\delta+1)\right. \\
& \left.+\delta \frac{x^{2}\left(c^{*}\right)}{c^{*}}\left\{c^{*} \frac{\frac{d^{2} x^{2}\left(c^{*}\right)}{d\left(c^{2}\right)^{2}}}{\frac{d x^{2}\left(c^{*}\right)}{d c^{2}}}\right\}\right]
\end{aligned}
$$

$-x^{2}\left(c^{*}\right) \frac{U^{\prime \prime}\left(x^{2}\left(c^{*}\right)\right)}{U^{\prime}\left(x^{2}\left(c^{*}\right)\right)}$ is the coefficient of relative risk aversion of the $U$ function and measures its degree of concavity. $c^{*} \frac{\frac{d^{2} x^{2}\left(c^{*}\right)}{d\left(c^{2}\right)^{2}}}{\frac{d x^{2}\left(c^{*}\right)}{d c^{2}}}$ is a similar measure of convexity for $x^{2}\left(c^{*}\right)$. This condition therefore requires that the $x$ function is not so convex as to overwhelm the concavity of $U$.

It is also clear that we can choose the $x^{2}\left(c^{2}\right)$ function such that it satisfies the conditions of proposition 1 , but violates the second order condition above at $c^{2}=c^{*}$. Which means that the maximization problem has a local minimum at $c^{*}: c^{*}$ cannot be the value of $c^{2}\left(y^{1}\right)$ for any $y^{1}$.

Therefore since $c^{2}\left(y^{1}\right)$ is an increasing function, either $c^{2}$ is discontinuous or $c^{2}\left(y^{1}\right) \rightarrow \bar{c}<c^{*}$ as $y^{1} \rightarrow \infty$. But the latter case is impossible as long as we assume that

$$
\frac{d x^{2}\left(c^{2}\right)}{d c^{2}}>\varepsilon>0 \text { for } c^{2} \leq \bar{c}
$$

and

$$
U^{\prime}(x) \rightarrow 0 \text { as } x \rightarrow \infty .
$$

This follows from the fact that if $c^{2}$ remains bounded above by $\bar{c}, x^{1} \rightarrow \infty$ as $y^{1} \rightarrow \infty$, and therefore the right hand side of the modified Euler equation goes to 0 (because of our assumption that $U^{\prime}(x) \rightarrow 0$ as $x \rightarrow \infty$ ) while the left hand side remains bounded away from zero.

It follows that under these conditions, $c^{2}\left(y^{1}\right)$ must have a discontinuity and "jump over" $c^{*}$.

This result reinforces the discussion earlier about the myopia of the poor. Notice that here two individuals with identical discount rates but with different 
initial wealth levels can end up with very different levels of apparent patience: the initially poor agent will appear to be impatient and the initially rich one will appear to be patient.

\subsection{Precautionary savings}

With standard preferences, it is well-known that an increase in income uncertainty in the second period (i.e. a mean preserving spread in the distribution of $y^{2}$ ) will increase savings in a safe asset as long the single-period indirect utility function exhibits prudence. In our environment the single-period indirect utility function would be given by

$$
W(c)=\max _{x} U(x)+V(c-x) .
$$

If we were to assume that there is a safe technology for transferring wealth across time $\left(f^{2}\left(w^{1}, \theta\right)=R w^{1}\right.$, where $R$ is a constant), the condition for there to be precautionary savings would be $W^{\prime \prime \prime}(c)>0$. A sufficient condition for that is that both $U$ and $V$ have non-negative third derivatives (and at least one of them is strictly positive).

With our kind of preferences this condition is no longer sufficient. To see this, recall the modified Euler equation for this case:

$$
\delta R E_{\theta^{\prime}}\left\{\frac{d U\left(x^{2}\left(c^{2}\left(\theta^{\prime}\right)\right)\right)}{d x^{2}} \frac{d x^{2}\left(c^{2}\left(\theta^{\prime}\right)\right)}{d c^{2}}\right\}=U^{\prime}\left(x^{1}\right) .
$$

Following the logic of precautionary savings in the standard model, it is clear that in this case, a mean preserving spread in $c^{2}$ will lead to lower $x^{1}$ if the function

$$
H(c)=\frac{d U(x(c))}{d x} \frac{d x((c))}{d c}
$$

is convex as a function of $c$. Taking derivatives twice (assuming differentiability) we can write

$H^{\prime \prime}(c)=\frac{d^{3} U(x)}{d x^{3}}\left[\frac{d x((c))}{d c}\right]^{3}+3 \frac{d^{2} U(x(c))}{d x^{2}} \frac{d^{2} x((c))}{d c^{2}}\left[\frac{d x((c))}{d c}\right]^{2}+\frac{d U(x(c))}{d x} \frac{d^{3} x((c))}{d c^{3}}$.

Several things become clear from this expression. First we do have the standard precautionary savings effect coming in as long as $\frac{d U(x(c))}{d x}$ is convex as a function of $c$ : this is captured by the first term in the above expression, which is positive if $\frac{d U(x(c))}{d x}$ is convex. However, there are two additional, potentially countervailing effects. One comes from the fact that $\frac{d x(c)}{d c}$ may not be convex as a function of $c$. This is what the last term says. The other comes from the correlation between $\frac{d U(x(c))}{d x}$ and $\frac{d x(c)}{d c}$ which may not be positive: This is the middle term above.

Indeed under DTC, $\frac{d U(x(c))}{d x}$ and $\frac{d x(c)}{d c}$ move in opposite directions when $c$ goes up and hence the middle term is always negative. This has a very intuitive explanation: The whole point of precautionary savings is to raise $x$ consumption levels in the state of the world when $c^{2}$ is particularly low. But in the DTC, 
$\frac{d x(c)}{d c}$ is particularly low when $c$ is low, and as a result, saving more does not help very much in terms of raising $x$ consumption in when $c$ is low. Therefore, the DTC partially defeats the purpose of saving more to protect against low $c^{2}$ states. ${ }^{29}$ Notice that the discussion so far has presumed differentiability of $x(c)$.In particular we will focus on the case where there is no poverty trap. Hence the failure of NDTC consumers to hold precautionary savings is independent of the poverty trap proposition above.

To summarize, we have the following Proposition:

Proposition 6 Assume that the distribution of $y^{2}$ is described by a family $G(y, \gamma)$ which has support on $[\underline{y}, \bar{y}]$, with increases in the scalar $\gamma$ representing mean preserving spreads in the distribution of $y$. Define $x^{1}(\gamma)$ to be the optimal choice of $x^{1}$ for each value of $\gamma$, and assume that in an open neighborhood of $\gamma^{*}$, $N_{\gamma^{*}}, x^{1}$ is differentiable as a function of $\gamma$. Define $c^{2}\left(y^{2}, \gamma\right)=R\left(y^{1}-x^{1}(\gamma)\right)+y^{2}$ and assume that for $\gamma \in N_{\gamma^{*}}$, the values of $c^{2}\left(y^{2}, \gamma\right)$ fall into the non-empty interval $[\underline{c}, \bar{c}]$. Then under NDTC, as long as $U^{\prime \prime \prime}(x(c)) \geq 0$ and $\frac{d^{3} x((c))}{d c^{3}} \geq 0$ for $c \in[\underline{c}, \bar{c}]$, for any $\gamma \in N_{\gamma^{*}}>\gamma^{*}, x^{1}(\gamma)<x^{1}\left(\gamma^{*}\right)$, i.e. a mean preserving spread in the distribution of $y^{2}$ reduces $x^{1}$. On the other hand under DTC, even if $\frac{d^{3} x((c))}{d c^{3}} \geq 0, U^{\prime \prime \prime}(x(c)) \geq 0$, and $V^{\prime \prime \prime}(z(c)) \geq 0$ for $c \in[\underline{c}, \bar{c}]$, it is possible that a mean preserving spread in the distribution of $y^{2}$ raises $x^{1}$.

Proof. The proof that under NDTC, first period consumption goes down when $y^{2}$ becomes more uncertain, is exactly the same as the proof of a precautionary demand for savings as long as the function $H(c)=\frac{d U(x(c))}{d x} \frac{d x((c))}{d c}$, defined above, is convex. From the expression derived above, this is always true when $\frac{d^{3} x((c))}{d c^{3}} \geq$ 0 for $c \in[\underline{c}, \bar{c}]$.

To prove that this condition does not guarantee the same result under DTC, consider the following example.

Let $U(x)=\ln x$ and $x(c)$ be described

$$
\begin{aligned}
& x(c)=\alpha c, c \leq \underline{c}, 0<\alpha<1 \\
& x(c)=A e^{\beta c}, \bar{c}>c>\underline{c} \\
& x(c)=\widetilde{\alpha} c-\gamma, c \geq \bar{c}, 0<\widetilde{\alpha}<1, \gamma>0
\end{aligned}
$$

To ensure $x(c)$ is differentiable, continuous and increasing everywhere, assume that

$$
\begin{aligned}
\alpha \underline{c} & =A e^{\beta \underline{c}} \\
\alpha & =\beta A e^{\beta \underline{c}} \\
\widetilde{\alpha} \bar{c} & =A e^{\beta \bar{c}}-\gamma \\
\widetilde{\alpha} & =\beta A e^{\beta \bar{c}}
\end{aligned}
$$

\footnotetext{
${ }^{29}$ On the other hand, the presence of this term also means that in the NDTC, we can get a precautionary savings effect even when $\frac{d^{3} U(x)}{d x^{3}}=0$, since under NDTC $\frac{d^{2} U(x(c))}{d x^{2}}$ and $\frac{d^{2} x((c))}{d c^{2}}$ are both negative and hence the product is positive.
} 
which together imply that $\bar{c}$ has to be equal to $\frac{1}{\beta}$ and that $\alpha<\widetilde{\alpha}$. Under these assumptions

$$
\frac{d x(c)}{d c}=\beta x \text { for } \underline{c}<c^{2}<\bar{c} .
$$

Therefore $\frac{d x^{2}\left(c^{2}\right)}{d c^{2}}$ is increasing as long as $c^{2}$ is between $\underline{c}<c^{2}<\bar{c}$, and constant otherwise. We assume that at $\gamma^{*}$ the distribution of $y^{2}$ is such that $\underline{c}<c^{2}<\bar{c}$. for all realizations of $\theta^{\prime}$. Then this will continue to be true for a small perturbation in the distribution of $y^{2}$ and we can assume that $\frac{d x^{2}\left(c^{2}\right)}{d c^{2}}=\beta x^{2}$ (and therefore DTC) everywhere in the relevant range. Moreover

$$
\frac{d x^{3}(c)}{d c^{3}}=\beta \frac{d x^{2}(c)}{d c^{2}} \geq 0
$$

as required by the condition of the Proposition.

Substituting this in the modified Euler equation gives us

$$
\begin{aligned}
\delta R E_{\theta^{\prime}}\left\{\frac{1}{x^{2}\left(c\left(\theta^{\prime}\right)\right)} \beta x^{2}\left(c\left(\theta^{\prime}\right)\right)\right\}= & U^{\prime}\left(x^{1}\right) \\
& \text { or } \\
\beta \delta R= & U^{\prime}\left(x^{1}\right)
\end{aligned}
$$

In other words, the right hand side is now a constant: Shifts in the distribution of $y^{2}$ (mean-preserving or otherwise) have no effect on the decision to save as long as $c^{2}$ remains in the relevant range.

To complete the proof we need to show that $U^{\prime}$ and $V^{\prime}$ are convex. Now, $U(x)=\ln x$, so $U^{\prime \prime \prime}>0 . V(z)$ has to be defined to generate the chosen $x(c)$ function:

$$
V(z)=\int_{0}^{z} U^{\prime}(g(y)) d y
$$

where $x=g(z)$ is the relationship between the optimizing values of $x$ and $z$ for the same value of $c$. Therefore

$$
\begin{aligned}
V^{\prime}(z) & =U^{\prime}(g(z)) \\
V^{\prime \prime}(z) & =U^{\prime \prime}(g(z)) g^{\prime}(z) \\
V^{\prime \prime \prime}(z) & =U^{\prime \prime \prime}(g(z))\left[g^{\prime}(z)\right]^{2}+U^{\prime \prime}(g(z)) g^{\prime \prime}(z)
\end{aligned}
$$

Now since $\frac{d x}{d c}=\beta x$ and $\frac{d z}{d c}=1-\beta x$,

$$
\begin{aligned}
g^{\prime}(z)= & \frac{d x}{d z}=\frac{\beta x}{1-\beta x} \\
g^{\prime \prime}(z)= & \frac{d x}{d z}=\frac{\beta}{(1-\beta x)^{2}} \frac{\beta x}{1-\beta x}
\end{aligned}
$$


Therefore

$$
\begin{aligned}
V^{\prime \prime \prime}\left(z^{2}\right)= & \frac{2}{\left(x^{2}\right)^{3}}\left(\frac{\beta x^{2}}{1-\beta x^{2}}\right)^{2} \\
& -\frac{1}{\left(x^{2}\right)^{2}} \frac{\beta}{\left(1-\beta x^{2}\right)^{2}} \frac{\beta x^{2}}{1-\beta x^{2}} \\
= & \frac{\beta^{2}}{x^{2}\left(1-\beta x^{2}\right)^{2}}\left[2-\frac{1}{1-\beta x^{2}}\right]
\end{aligned}
$$

This is positive in the relevant range as long as

$$
\frac{1}{1-\beta x(\bar{c})}<2
$$

Moreover for $c^{2}$ outside the range $[\underline{c}, \bar{c}] z$ is linear in $x$, and therefore $V^{\prime \prime \prime}$ has the same sign as $U^{\prime \prime \prime}$. Therefore the condition for precautionary savings with conventional preferences (that both $U^{\prime \prime \prime}$ and $V^{\prime \prime \prime}$ are strictly positive) holds everywhere. Yet there is no precautionary savings.

A few points about this result are worth emphasizing. First, the condition that $x^{1}(\gamma)$ is differentiable is imposed for expositional purposes. Under NDTC, we know that $x^{1}(\gamma)$ is always continuous as a function of the underlying parameters and therefore it is always possible to establish a variant of this proposition for that case without any differentiability. Under DTC, we are only trying to find a counterexample, and allowing for the possibility that $x^{1}(\gamma)$ can be discontinuous only makes easier to construct such an example. Second, the condition that $\frac{d^{3} x((c))}{d c^{3}} \geq 0$ is necessary to get the NDTC result. It is possible to construct examples where $\frac{d^{3} x((c))}{d c^{3}}<0$, and there is no precautionary savings even under NDTC.

\subsection{Implications for the Structure of Investments}

Standard utility theory has some clear and useful implications about the nature of investment demand. Specifically, it tells us that while the minimum scale of a project is a consideration (because of credit constraints), in addition to the rate of return (we assume there is no risk), the maximum scale of investment is not a consideration. You may not go all the way up to the maximum scale, but the fact that there is a maximum scale is irrelevant as long as the project has a high enough mean return. This is no longer necessarily true in our model of temptations: Individuals facing declining temptations will be unwilling to invest in high returns investments if the scale is too small. This captures the lay intuition that investments may be unimportant unless they significantly change one's circumstances.

Assume that the period one self has been offered access to a set of new investment technologies (in addition to what was already available to him). We are interested in whether he would take it up. These new investments are described by three features. Assume that each investment $\iota$ is described by its 
return $R(\iota)$, minimum size $s(\iota)$, and maximum size $S(\iota) \cdot{ }^{30}$ If he undertakes the investment $\iota$, he can choose an investment level $I$ between $s(\iota)$ and $S(\iota)$. Period 1 self will then have $I$ units less to spend but period 2 self will receive $R(\iota) I$ returns. In this highly abstract setup, we can examine the rank-ordering of investments. If individuals are willing to undertake $\iota$ what can we say about any other $\iota^{\prime}$ that they would also be willing to undertake?

To analyze this rigorously we focus on a setting where both $y^{1}$ and $y^{2}$ are deterministic, borrowing is ruled out (allowing some borrowing would not change anything essential, but makes some of the arguments more tedious) and there is "base" investment technology, $f\left(w^{1}\right)=R_{0} w^{1}, R_{0}>1$. The investor is now offered the option of investing in one additional technology with the understanding that he still has the option of investing as much as he wants in the base technology (subject, as before, to the constraint that he cannot borrow).

Proposition 7 In this setting under NDTC, if the investor is willing to undertake an investment $\iota=\{R(\iota), s(\iota), S(\iota)\}$ then he will always be willing to undertake an investment $\iota^{\prime}=\left\{R\left(\iota^{\prime}\right), s\left(\iota^{\prime}\right), S\left(\iota^{\prime}\right)\right\}$ as long as $R\left(\iota^{\prime}\right) \geq R(\iota)$ and $s\left(\iota^{\prime}\right) \leq s(\iota)$. In other words, minimum scale and returns summarize the investment. In contrast, if $S(\iota)>S\left(\iota^{\prime}\right)$, under DTC there exist situations where this is not true even if $R\left(\iota^{\prime}\right)>R(\iota)$ and $s\left(\iota^{\prime}\right)<s(\iota)$.

Proof. Define $W\left(c^{1}, c^{2}\right)$ to be the period 1 self's maximand, i.e.

$$
W^{1}\left(c^{1}, c^{2}\right)=W\left(c^{1}\right)+U\left(x^{2}\left(c^{2}\right)\right) .
$$

In the NDTC, since $x^{2}$ is a concave function of $c^{2}, W^{1}\left(c^{1}, c^{2}\right)$ is a strictly concave function of the vector $\left(c^{1}, c^{2}\right)$.

Suppose period 1 self's optimal choice when offered the option $\iota$ is to invest an amount $I>0$ in $\iota$ and to consume an amount $c^{1}$ in period 1 . The amount he invests in the base technology is therefore $y^{1}-I-c^{1}$. Clearly in the absence of credit $y^{1}-I-c^{1}$ must be non-negative. $c^{2}$ in this case is given by

$$
c^{2}=I R(\iota)+\left(y^{1}-I-c^{1}\right) R_{0}+y^{2}
$$

If instead he had chosen not to invest in $\iota$, he would have consumed an amount $\widetilde{c}^{1}$ in period 1 and invested $y^{1}-\widetilde{c}^{1}$ in the base technology. Therefore

$$
\widetilde{c}^{2}=\left(y^{1}-\widetilde{c}^{1}\right) R_{0}+y^{2} .
$$

By the fact that the investor chose to invest

$$
W\left(c^{1}, c^{2}\right) \geq W\left(\widetilde{c}^{1}, \widetilde{c}^{2}\right)
$$

Now consider the vector $\left(\lambda c^{1}+(1-\lambda) \widetilde{c}^{1}, \lambda c^{2}+(1-\lambda) \widetilde{c}^{2}\right), 1>\lambda>0$ : Clearly, by the strict concavity of $W, W\left(\lambda c^{1}+(1-\lambda) \widetilde{c}^{1}, \lambda c^{2}+(1-\lambda) \widetilde{c}^{2}\right)>W\left(\widetilde{c}^{1}, \widetilde{c}^{2}\right)$.

\footnotetext{
${ }^{30}$ The model also has implications for the timing of investment which we do not investigate in this current version.
} 
The only constraint is whether $\left(\lambda c^{1}+(1-\lambda) \widetilde{c}^{1}, \lambda c^{2}+(1-\lambda) \widetilde{c}^{2}\right)$ is in the option set. Note however that we can write

$$
\begin{aligned}
& \lambda c^{2}+(1-\lambda) \widetilde{c}^{2} \\
= & \lambda\left(I R(\iota)+\left(y^{1}-I-c^{1}\right) R_{0}+y^{2}\right) \\
& +(1-\lambda)\left(\left(y^{1}-c^{1}\right) R_{0}+y^{2}\right) \\
= & \lambda I R(\iota)+\left(y^{1}-\lambda I-c^{1}\right) R_{0}+y^{2}
\end{aligned}
$$

In other words the investor can choose the vector $\left(\lambda c^{1}+(1-\lambda) \widetilde{c}^{1}, \lambda c^{2}+(1-\lambda) \widetilde{c}^{2}\right)$ by investing an amount $\lambda I$ in asset $\iota$. Now by investing an amount $\lambda I$ in asset $\iota^{\prime}$ with $R\left(\iota^{\prime}\right) \geq R(\iota)$ the investor can generate a vector $\left(\lambda c^{1}+(1-\lambda) \widetilde{c}^{1}, \lambda I R\left(\iota^{\prime}\right)+\right.$ $\left.\left(y^{1}-\lambda I-c^{1}\right) R_{0}+y^{2}\right)$, which has the same first element and a second element which is no smaller than what he gets by investing $\lambda I$ in $\iota$. In other words,

$$
\begin{aligned}
& W\left(\lambda c^{1}+(1-\lambda) \widetilde{c}^{1}, \lambda I R\left(\iota^{\prime}\right)+\left(y^{1}-\lambda I-c^{1}\right) R_{0}+y^{2}\right) \\
\geq & W\left(\lambda c^{1}+(1-\lambda) \widetilde{c}^{1}, \lambda c^{2}+(1-\lambda) \widetilde{c}^{2}\right) \\
> & W\left(\widetilde{c}^{1}, \widetilde{c}^{2}\right) .
\end{aligned}
$$

In other words as long as we can make sure that the amount invested in asset $\iota^{\prime}$ is feasible, i.e. set $\lambda I$ between $s\left(\iota^{\prime}\right)$ and $S\left(\iota^{\prime}\right)$, then there will be investment in $\iota^{\prime}$. But since $s\left(\iota^{\prime}\right) \leq s(\iota)$, it will always be possible to set $\lambda$ so that $s\left(\iota^{\prime}\right) \leq \lambda I \leq$ $S\left(\iota^{\prime}\right)$. Therefore there will always be some investment in $\iota^{\prime}$.

Under DTC, $W\left(c^{1}, c^{2}\right)$ is not necessarily concave. To see where things might break down when $W\left(c^{1}, c^{2}\right)$ is not concave, consider the following special preferences:

$$
\begin{aligned}
V(z)= & a z, z \leq \bar{c} \\
= & a \bar{c}, z>\bar{c} \\
& \text { and } \\
U(0)= & 0,0<U^{\prime}(0)<a, U^{\prime \prime}(x)<0
\end{aligned}
$$

In the second period, these preferences imply that

$$
\begin{aligned}
z^{2}\left(c^{2}\right) & =c^{2}, z \leq \bar{c} \\
& =\bar{c}, z>\bar{c}
\end{aligned}
$$

Given these preferences, anyone with $y^{1}$ and $y^{2}$ such that $R_{0} y^{1}+y^{2}<\bar{c}$, will not save as long as the base technology is the only available technology, because he faces a $z^{\prime}(c)$ of 1 . Moreover, given that $R_{0}>1, y^{1}$ must be less than $\bar{c}$ and therefore period 1's self will consume all of $y^{1}$ in the form of the $z$ good. His two period utility is therefore ay ${ }^{1}$.

Next, assume that he is willing to invest the entire amount $y^{1}$ in technology ı. This requires that

$$
R(\iota) y^{1}+y^{2}>\bar{c}
$$

that

$$
\delta U\left(R(\iota) y^{1}+y^{2}-\bar{c}\right)>a y^{1} .
$$


and that

$$
\delta R(\iota) U^{\prime}\left(R(\iota) y^{1}+y^{2}-\bar{c}\right)>a .
$$

Clearly we can find a $R(\iota)$ large enough for which these conditions hold.

Finally assume that there is an $\iota^{\prime}$ such that $R\left(\iota^{\prime}\right)>R(\iota), s\left(\iota^{\prime}\right)<s(i)$ and $S\left(\iota^{\prime}\right)<S(\iota)$. Now if

$$
R\left(\iota^{\prime}\right) S\left(\iota^{\prime}\right)+y^{2}<\bar{c}
$$

there will obviously not be any investment in $\iota^{\prime}$,even though it has a higher per dollar return and lower minimum scale. The logic of this construction makes clear that it can easily be extended to the case where both $V$ and $z^{2}\left(x^{2}\right)$ are differentiable functions.

This result is important, we feel, for two reasons. First, some of the high return investments which have been brought up in the literature as instances of a puzzling unwillingness to invest are naturally capped. Fertilizer, for example, may earn very high rates of return (Duflo, Kremer and Robinson (2009)) and has no obvious minimum scale but the maximum scale at which it can be applied is capped by the amount of land you own. Similarly, Kremer, Lee and Robinson (2009) argue convincingly that stocking behavior on phone cards is an example of an unexploited high return investment, but once again these are investments that are limited in terms of maximum scale: The optimal stocking pattern would involve holding a few more cards, but not a lot more. Second, even when projects have no natural maximum scale, the presence of credit constraints makes them have one. Therefore, even if land is a constraint on how much the farmers studied by Duflo, Kremer and Robinson (2009) invest in fertilizer, credit might be: Farmers might prefer to consume everything they have, because given the credit constraints, any interesting projects are beyond their reach. For both of these reasons, empirical work on investment decisions should also pay attention to the maximum feasible scale.

\subsection{Demand for Credit}

Declining temptations also have implications for the benefits and costs of credit. In the traditional model, access to credit is clearly good: it increases the opportunity set. In models with self-control problems, credit can potentially hurt. Specifically, today's self could be made worse off if tomorrow's self has access to credit. This general feature of self-control models has more specific implications if we focus on declining temptations.

To fully capture commitment benefits in this context, we need to introduce a third ("zero") period. In the existing two period model, commitment has benefits only if the first period can restrict the type of consumption ( $x$ goods rather than $z$ goods) in the second period. But in this section and those that follow, we will be interested in what is effectively a much cruder commitment mechanism: the restriction of overall level of consumption. In two periods, this would be a meaningless concept since the second period self would consume all 
the wealth in any case. In a three period model, however, the zero period self can undertake actions that restrict the first period self's ability to consume.

Since we are interested only in the investment and commitment demands of this period zero self, we assume this self has no consumption. Instead he or she merely maximizes $U\left(x^{1}\right)+\delta U\left(x^{2}\right){ }^{31}$ The other two periods are as before.

In this subsection, we focus on the case where the zero period self has a single decision: whether or not to allow the period one self to have access to consumption credit. The period 1 self has no automatic access to credit markets but the period zero self may give him specific types of access. The point of credit is to allow period 1 self to move consumption from period 2 to period 1 ; there are investment opportunities or opportunities for lending. We are interested in the types of access that the period zero self would be willing to allow his future selves. Suppose that a loan $\lambda$ is defined by two characteristics: $r(\lambda)$, the interest rate and a maximum loan size $L(\lambda)$. If the period one self is allowed a loan of type $\lambda$, he can choose to borrow some amount between 0 and $L(\lambda)$ and have the period two self repay $r(\lambda)$ times that amount.

We then ask question of the type: if the zero period self allows a loan of type $\lambda$, will he allow a loan of type $\lambda^{\prime}$ ? The key insight is that the shape of temptation places structure on the demand for commitment. It is well-known that the presence of temptations that cause the period 1 self to over-consume would make the period zero self interested in placing a limit on how big the maximum loan size $L(\lambda)$ can be. What is more surprising is that in the presence of declining temptations the zero period self might have an additional interest in placing limits on how small it can be.

Proposition 8 Under NDTC, if the period zero self is willing to allow a loan $\lambda=\{r(\lambda), L(\lambda)\}$, he will always willing to allow loan $\lambda^{\prime}=\left\{r\left(\lambda^{\prime}\right), L\left(\lambda^{\prime}\right)\right\}$ as long as $r(\lambda)=r\left(\lambda^{\prime}\right)$ and $L\left(\lambda^{\prime}\right) \leq L(\lambda)$. Under DTC there will exist situations where he is willing to allow a loan $\lambda=\{r(\lambda), L(\lambda)\}$, but not a loan $\lambda^{\prime}=\left\{r\left(\lambda^{\prime}\right), L\left(\lambda^{\prime}\right)\right\}$ where $r(\lambda)=r\left(\lambda^{\prime}\right)$, but $L\left(\lambda^{\prime}\right)<L(\lambda)$.

Proof. NDTC: In this case since $x^{1}\left(c^{1}\right)$ and $x^{2}\left(c^{2}\right)$ are both concave, Period O's utility function

$$
\left.\Pi_{0}(L)=U\left(x^{1}\left(y^{1}+L\right)\right)+\delta U\left(x^{2}\left(y^{2}-\operatorname{Lr}(\lambda)\right)\right)\right)
$$

is concave as a function of $L$, the actual loan amount. Assume that period 0 self permits a loan product $\lambda=\{r(\lambda), L(\lambda)\}$, but not a loan $\lambda^{\prime}=\left\{r\left(\lambda^{\prime}\right), L\left(\lambda^{\prime}\right)\right\}$ where $r(\lambda)=r\left(\lambda^{\prime}\right)=r$,but $L\left(\lambda^{\prime}\right)=L^{\prime}<L(\lambda)=L$.. This means that

$$
\begin{aligned}
\Pi_{0}(\widetilde{L}) & =U\left(x^{1}\left(y^{1}+\widetilde{L}\right)\right)+\delta U\left(x^{2}\left(y^{2}-r \widetilde{L}\right)\right) \\
& \geq U\left(x^{1}\left(y^{1}\right)\right)+\delta U\left(x^{2}\left(y^{2}\right)\right)=\Pi_{0}(0)
\end{aligned}
$$

\footnotetext{
${ }^{31}$ In what follows, what matters is that the period 0 self is effectively more patient than period 1 self, so technically the period 0 self could also maximize $U\left(x^{1}\right)+c V\left(z^{1}\right)+\delta\left[U\left(x^{2}\right)+\right.$ $\left.c V\left(z^{2}\right)\right]$ for some $c>0$ without changing our analysis in any signficant way.
} 
but

$$
\begin{aligned}
\Pi_{0}\left(\widetilde{L}^{\prime}\right) & =U\left(x^{1}\left(y^{1}+\widetilde{L}^{\prime}\right)\right)+\delta U\left(x^{2}\left(y^{2}-r \widetilde{L}^{\prime}\right)\right) \\
& <U\left(x^{1}\left(y^{1}\right)\right)+\delta U\left(x^{2}\left(y^{2}\right)\right)=\Pi_{0}(0)
\end{aligned}
$$

where $\widetilde{L}, \widetilde{L}^{\prime}$ are the loan amount actually chosen under $\lambda, \lambda^{\prime}$. Now any loan amount that is less than $L^{\prime}$ could have been chosen both under under $\lambda$ and $\lambda^{\prime}$. Therefore if $\widetilde{L} \leq L^{\prime}$, there is no reason why a decision maker who allows $\lambda$ would be unwilling to allow $\lambda^{\prime}$ since $\widetilde{L}$ will be chosen under both. The interesting case is where $\widetilde{L} \geq L^{\prime} \geq \widetilde{L}^{\prime}$. In this case $\widetilde{L}^{\prime}$ is between $\widetilde{L}$ and a loan size of 0 . But then, by the concavity of $\Pi_{0}(L), \Pi_{0}\left(\widetilde{L}^{\prime}\right)$ has to be no less than $\Pi_{0}(0)$, which directly contradicts what we said above. This contradiction proves that $\lambda^{\prime}$ will be allowed if $\lambda$ is allowed.

DTC: To show that this is not necessarily true in DTC, consider the example from the previous sub-section where

$$
\begin{aligned}
V(z)= & a z, z \leq \bar{c} \\
= & a \bar{c}, z>\bar{c} \\
& \text { and } \\
U(0)= & 0,0<U^{\prime}(0)<a, U^{\prime \prime}(x)<0
\end{aligned}
$$

In the second period, these preferences imply that

$$
\begin{aligned}
z^{2}\left(c^{2}\right) & =c^{2}, z \leq \bar{c} \\
& =\bar{c}, z>\bar{c} .
\end{aligned}
$$

Also set $r(\lambda)=1$. Therefore

$$
x^{1}+z^{1}+x^{2}+z^{2}=y^{1}+y^{2}
$$

Assume that $y^{1}=\alpha \bar{c}(0 \leq \alpha \leq 1), y^{2}=\bar{c}+k$ and there is no borrowing allowed. Call this scheme of $(1,0)=\lambda_{0}$. Under this scheme, the period 1 self spends his entire income on $z$ while the period 2 self spends his first $\bar{c}$ on $z$ but the remaining $k$ goes to $x$. Therefore $\Pi_{0}\left(\lambda_{0}\right)=\delta U(k)$

Now assume that there exists a loan $\lambda_{1}=\left(1, L\left(\lambda_{1}\right)\right)$, where $L\left(\lambda_{1}\right)<(1-\alpha) \bar{c}<$ $k$. For simplicity call this $\gamma \bar{c}, \gamma<1-\alpha$. Given the assumed preferences, the period 1 self will want to borrow as much as he can and spend it all on $z$. The period 2 self spends the $k-\gamma \bar{c}$ that remains after satisfying his appetite for $z$ on $x$. Hence $\Pi_{0}\left(\lambda_{1}\right)=\delta U(k-\gamma \bar{c})<\delta U(k)$. Therefore, the period 0 self does not stand to benefit (and actually is hurt by) any loan with a maximal loan size until the threshold of $(1-\alpha) \bar{c}$ and will refuse all of those.

A necessary condition for any loan he would allow is therefore $L(\lambda)>$ $(1-\alpha) \bar{c}$. Assume $L\left(\lambda_{2}\right)=(1-\alpha) \bar{c}+\varepsilon$. Now the period 1 self actually spends an amount $\varepsilon$ on $x$ because he can satiate his desire for $z$. Therefore $\Pi_{0}\left(\lambda_{2}\right)=U(\varepsilon)+\delta U(k-(1-\alpha) \bar{c}-\varepsilon)$. 
Now $U(\varepsilon) \geq \delta[U(k)-U(k-(1-\alpha) \bar{c}-\varepsilon)]$, for $\alpha$ sufficiently close to 1 since $U$ is strictly concave. Therefore we have shown that there exists

$$
\lambda_{2}=\left(r\left(\lambda_{2}\right), l\left(\lambda_{2}\right), L\left(\lambda_{2}\right)\right) \text { and } \lambda_{1}=\left(r\left(\lambda_{1}\right), l\left(\lambda_{1}\right), L\left(\lambda_{1}\right)\right)
$$

with

$$
r\left(\lambda_{1}\right)=r\left(\lambda_{2}\right), l\left(\lambda_{1}\right)=l\left(\lambda_{2}\right), L\left(\lambda_{1}\right)<L\left(\lambda_{2}\right)
$$

where period 0 accepts $\lambda_{2}$ but not $\lambda_{1}$.

The intuition behind this result is simple. When temptations are constant, the only concern for the zero-period self is over-borrowing. Over-borrowing hurts the period zero self in two ways: (i) Exaggerating the difference in consumption between the period one and two selves and (ii) Engaging in borrowing at a higher rate than the period zero self would want. ${ }^{32}$ Self zero must weigh these costs against the potential for borrowing to facilitate investments. As a result, person zero can only want to limit the possibility for borrowing. When temptations are declining, however, there is an offsetting force. When the period one self borrows a small amount, all of it might go into $z$, but when he gets to borrow more, declining temptations kick in and he spends more of the loan proceeds on $x .^{33}$

These results, we feel, are helpful in helping us parse credit contracts that we observe. Consider two different contracts: microfinance and credit cards. Micro-finance offers only larger loans while credit cards only offer small loans. In the model with constant temptations, and no lumpy investment, the period zero self may accept to get a credit card but refuse a microfinance loan, but never the other way around. Declining temptations can explain why we may observe the opposite: resistance to credit cards (or the equivalent) while support for micro-credit. ${ }^{3435}$

\footnotetext{
${ }^{32}$ Period zero self discounts at rate $\delta$ while period one self discounts at $\delta\left(1-z^{\prime}(c)\right)$. Interest rates between those two bounds would induce inefficient borrowing.

${ }^{33}$ Given that the problem comes from 1 taking a small loan and spending it mainly on $z$ it might seem that putting a floor on loan size would achieve the same goal in this environment. This is however not true: In this case a floor only matters if it is binding; if the period 1 self wants to borrow less, then the period 0 self would also want him to borrow less and would want to lower the floor. A minimum loan size would help if, on the other hand, there were a lumpy investment opportunity (or a consumer durable) that period 1 self could, in principle, carry out, but even with the biggest available loan, carrying out the investment would require him to consume less today. In that case, since he values consumption today relative to consumption tomorrow more than the period zero self, he may be reluctant to carry it out even when period zero would want him to. In this situation offering the option of borrowing a small amount may not be in period zero's interest because period 1 is already overconsuming. On the other hand, a larger loan is useful to 1 only if he complements it by saving more, which is what 0 wants. However the logic of this effect makes it clear that it would also arise in the constant temptation case.

${ }^{34}$ However it may be useful to add lumpy investment opportunities to our model since that combined with time inconsistency would explain why micro-finance loans have a minimum size.

${ }^{35}$ We do not explore here a different commitment feature of debt: the forced repayment that it implies. We conjecture that on this dimension as well, contracts which appear as microfinance contracts (big lump sum, combined with small repayment installments) help solve
} 


\subsection{Supply of Credit}

So far we have focused on the demand side: We now turn to the supply side of credit and investment opportunities. Consider an individual who is borrowing from a monopolistic money lender. Suppose a new investment arises that earns a rate of return higher than the money lender's cost of capital. If the money lender could price discriminate and offer a rate specifically for this investment, would the investment get made? Simple Coasian logic suggests it should. Yet there is a long tradition of arguing that the money lender has an incentive to block this investment either directly or by refusing to finance it, in order to maintain his power over the borrower (Bhaduri 1973). The logic is that the technological improvement will raise the earnings of those who used to borrow from the money-lender which in turn hurts the lender's profits through reduced borrowing. In short, the money-lender prefers to have his clients caught in a debt trap.

Clearly, if the technological innovation were to change the time structure of the borrower's earnings (so that his earnings become more present biased and therefore his incentive to borrow goes down) the money lender has every reason to feel threatened. However, as pointed out by Srinivasan (1994), if the investment requires spending in the present to increase future earnings, there is no reason why borrowing would go down and therefore the money lender should want to promote the innovation.

In the rest of this sub-section we will see that while the intuition proposed in the previous paragraph continues to hold under NDTC, the possibility of declining temptations reintroduces the possibility that Bhaduri had emphasized: The money-lender may indeed want block progress to keep the borrower in his thrall.

Assume that there is a time-inconsistent agent, who, as in previous subsection, lives for 3 periods but consumes $x$ goods and $z$ goods only in the last two periods. However the period 0 self only values $x$ consumption. Finally to limit the number of free parameters assume both the borrower and the lender do not discount future utilities, i.e., $\delta=1$

The individual earns $y$ in each of the last two periods and the period 1 self has the option of saving at a gross interest rate of 1 and borrowing additional resources from a money lender at an interest rate $R_{1}$ set by the money lender. Then the period 1 self will choose his borrowing $L_{1}$ to maximize

$$
W\left(y+L_{1}\right)+U\left(x\left(y-R_{1} L_{1}\right)\right) .
$$

Assume that this is maximized by choosing $L_{1}\left(R_{1}\right)$

Suppose the agent borrows from a profit maximizing monopoly lender who can only set the interest rate (i.e. he cannot set the amount borrowed as well) and whose (gross) opportunity cost of capital is $\rho>1$ per period. The lender therefore chooses $R_{1}$ to maximize $\left(L_{1}\left(R_{1}\right) R_{1}-\rho L_{1}\left(R_{1}\right)\right)$. Let $R_{1}^{o}$ be the interest rate that maximizes this expression. $\pi_{1}^{0}=\left(L_{1}\left(R_{1}^{0}\right) R_{1}^{0}-\rho L_{1} R_{1}^{0}\right)$ is the maximized level of profit.

temptation problems more so than credit card like contracts (small trickles of borrowing, combined with a big repayment). 
Now suppose an investment opportunity becomes available to the agent. It requires an investment of $I$ in period 0 and an action taken in period 0 , which has a utility cost of $E$. The purpose of introducing this cost is to make sure that the agent's lifetime earnings go strictly up if he undertakes the investment-in other words, the interest rate the lender charges cannot be so high that the agent ends up with the same income after the investment than he had before, because in that case he would prefer not to put in the effort that the investment requires. The investment, if undertaken, generates a revenue of $\phi I$ in period 2 .

Now given that the agent has no resources in period 0 , the investment requires a loan $L_{0}=I$ in period 0 . Suppose the money lender offers a loan of $I$ at interest rate $R_{0}$ in period 0 to be repaid when the investment pays off, i.e. in period 2.

However knowing that he will be richer in period 2, the agent may want to increase his consumption in period 1 by borrowing more from the money lender (he may also want to do the opposite, which is to prepay the loan he had taken out in period 0, but assume that the money-lender can block prepayment).

Consider the decision of how much to borrow in period 1 . If the interest rate set by the money lender in period 1 is $R_{1}$, the agent will maximize

$$
W\left(y+L_{1}\right)+U\left(x\left(y+\left(\phi-R_{0}\right) I-R_{1} L_{1}\right)\right)
$$

which yields $L_{1}\left(R_{0}, R_{1}\right)$. Period 0 takes this decision as given and chooses between investing and not investing: He invests if

$$
\begin{aligned}
& U\left(y+L_{1}\left(R_{0}, R_{1}\right)\right)+U\left(x\left(y+\left(\phi-R_{0}\right) I-R_{1} L_{1}\left(R_{0}, R_{1}\right)\right)\right)-E \\
\geq & U\left(y+L_{1}\left(R_{1}^{o}\right)\right)+U\left(x\left(y-R_{1}^{o} L_{1}\left(R_{1}^{o}\right)\right)\right)
\end{aligned}
$$

The problem is interesting only if the investment is worth doing. As a feasibility condition we assume that

$$
\begin{aligned}
& U\left(y+L_{1}\left(\rho, R_{1}^{o}\right)\right)+U\left(x\left(y+\left(\phi-\rho^{2}\right) I-R_{1}^{o} L_{1}\left(\rho, R_{1}^{o}\right)\right)\right)-E \\
\geq & U\left(y+L_{1}\left(R_{1}^{o}\right)\right)+U\left(x\left(y-R_{1}^{o} L_{1}\left(R_{1}^{o}\right)\right)\right)
\end{aligned}
$$

In other words, as long as the second period interest rate remains the same as what it is in the absence of investment, but the first period rate is set at the (two period) cost of capital, the project is worth doing. A necessary condition for this to be true is that $\phi>\rho^{2}$, since $E>0$. Note that this feasibility condition is exactly the thought experiment at the beginning of the section: the new technology is profitable relative to the money lender's cost of capital.

Under this feasibility condition, the lender always has the option of offering the agent an interest rate $\rho$ in period 0 , and an interest rate $R_{1}^{o}$ in period 1 and getting him to do the project. He can also always block it by setting $R_{0}=\infty$. The following result establishes that he will never want to block under NDTC but this is not true under DTC.

Proposition 9 In this setting under NDTC the moneylender will always be willing to lend the investor money to make the new investment possible. Under DTC there exist situations where this is not true. 
Proof. As noted above, under NDTC $U\left(x\left(y+\left(\phi-\rho^{2}\right) I-R_{1}^{o} L_{1}\left(\rho, R_{1}^{o}\right)\right)\right)$ is an increasing and strictly concave function of $y+\left(\phi-\rho^{2}\right) I-R_{1}^{o} L_{1}\left(\rho, R_{1}^{o}\right)$, while $W(\cdot)$ is always increasing and concave. We use this to first show that when $I$ goes up from 0 , keeping the interest rates unchanged, the borrower cannot strictly prefer to borrow less.

Suppose, to the contrary, the borrower borrows $L_{1}$ in period 1 when there is investment $I$ and $L_{1}^{\prime}$ when there is no investment, and $L_{1}^{\prime}>L_{1}$. By revealed preference it must be that

$$
\begin{array}{r}
W\left(y+L_{1}\right)+U\left(x\left(y+\left(\phi-\rho^{2}\right) I-R_{1}^{o} L_{1}\right)\right) \\
\geq \quad W\left(y+L_{1}^{\prime}\right)+U\left(x\left(y+\left(\phi-\rho^{2}\right) I-R_{1}^{o} L_{1}^{\prime}\right)\right)
\end{array}
$$

and

$$
\begin{array}{r}
W\left(y+L_{1}^{\prime}\right)+U\left(x\left(y-R_{1}^{o} L_{1}^{\prime}\right)\right) \\
\geq \quad W\left(y+L_{1}\right)+U\left(x\left(y-R_{1}^{o} L_{1}\right)\right)
\end{array}
$$

It follows from these two inequalities that

$$
\begin{aligned}
& U\left(x\left(y+\left(\phi-\rho^{2}\right) I-R_{1}^{o} L_{1}\right)\right)-U\left(x\left(y+\left(\phi-\rho^{2}\right) I-R_{1}^{o} L_{1}^{\prime}\right)\right) \\
\geq & U\left(x\left(y-R_{1}^{o} L_{1}\right)\right)-U\left(x\left(y-R_{1}^{o} L_{1}^{\prime}\right)\right) .
\end{aligned}
$$

Since $\phi>\rho^{2}$, this contradicts the concavity of $U(x(\cdot))$ unless

$$
\begin{aligned}
& U\left(x\left(y+\left(\phi-\rho^{2}\right) I-R_{1}^{o} L_{1}\right)\right)-U\left(x\left(y+\left(\phi-\rho^{2}\right) I-R_{1}^{o} L_{1}^{\prime}\right)\right) \\
= & U\left(x\left(y-R_{1}^{o} L_{1}\right)\right)-U\left(x\left(y-R_{1}^{o} L_{1}^{\prime}\right)\right) .
\end{aligned}
$$

which would imply that

$$
\begin{aligned}
& W\left(y+L_{1}\right)+U\left(x\left(y+\left(\phi-\rho^{2}\right) I-R_{1}^{o} L_{1}\right)\right) \\
= & W\left(y+L_{1}^{\prime}\right)+U\left(x\left(y+\left(\phi-\rho^{2}\right) I-R_{1}^{o} L_{1}^{\prime}\right)\right)
\end{aligned}
$$

Therefore the agent cannot strictly prefer to borrow less.

Since the lender's revenue is

$$
\left(R_{0}-\rho^{2}\right) I+\left(R_{1}-\rho\right) L_{1}
$$

This means that the lender can make himself at least as well off when there is investment as when there is no investment, by setting $R_{0}=\rho^{2}, R_{1}=R_{1}^{o}$ (our feasibility condition guarantees that the borrower will invest when offered these rates), since he gets to lend more (or at least no less). He will therefore lend money to the borrower for investment.

To see what changes under DTC assume that

$$
\begin{aligned}
V(z)= & a z, z \leq \bar{c}, a>1 \\
= & a \bar{c}, z>\bar{c} \\
& \text { and } \\
U(x)= & x
\end{aligned}
$$


Assume also that $\bar{c}>y$. Therefore, in the absence of the investment, it is always optimal for the period 1 self to borrow the full amount of $y$ if he borrows anything at all, since he gains nothing from leaving any amount less than $\bar{c}$ for period 2 to consume. However period 1 does have the option of saving his period 1 income and spending it in period 2 - assume that the gross interest rate on savings is 1. By borrowing and consuming everything, he gets a utility of

$$
a\left[y+\frac{y}{R_{1}}\right]
$$

under the assumption that $y+\frac{y}{R_{1}}<\bar{c} .{ }^{36}$ If he saves he gets

$$
[2 y-\bar{c}]
$$

This puts an upper bound on $R_{1}$ implicitly given by

$$
\frac{y}{R_{1}} \geq \frac{[2 y-\bar{c}]}{a}-y
$$

which only binds if $\frac{[2 y-\bar{c}]}{a}-y>0$. But since $\bar{c}>y$ and $a>1, \frac{[2 y-\bar{c}]}{a}-y$ must be negative, and therefore there is no constraint on how high $R_{1}$ can be. A monopolistic lender will set it to be infinite, and extract the borrower's entire second period income, i.e., $L_{1} \simeq 0$. Therefore the lender will earn an amount $y$ in this case.

If the investment does take place the borrower faces a similar choice: He can either save his period 1 earnings and get utility $2 y+\left(\phi-R_{0}\right) I-\bar{c}$ in period 2 , in which case $L_{1}=0$, and the lender makes no money from $L_{1}$, though he may still make money from the zero period loan. We will return to this option in a few paragraphs.

The alternative for the lender is to make sure that the borrower borrows in period 1. By the way the preferences have been specified, only the marginal units of spending in period 2 go into $x$ consumption, which is all that period 1 cares about. Moreover the marginal utility of $x$ spending is constant. Therefore if the period 1 self is prepared to move one unit of spending from period 2 to period 1 , he will want to do so for all the the other units of spending. In other words, if he borrows at all, he will borrow the entire amount $\frac{y+\left(\phi-R_{0}\right) I}{R_{1}}$.

Given that there is no $x$ consumption in period 2, the only value from the investment from the point of view of the period 0 self comes from period 1 consumption of $x$. Therefore it must be the case that there is some period 1 consumption of $x$ (otherwise the period 0 self will never agree to put in the effort). In other words, we must have

$$
y+\frac{y+\left(\phi-R_{0}\right) I}{R_{1}} \geq \bar{c} .
$$

\footnotetext{
${ }^{36}$ As we will show in the next few lines the solution to the monopolist's problem has $R_{1}=\infty$ and as a result this condition is implied by $y<\bar{c}$.
} 
Therefore the utility period 1 self gets from consuming his entire discounted income in period 1 has to be

$$
\left[y+\frac{y+\left(\phi-R_{0}\right) I}{R_{1}}-\bar{c}\right]+a \bar{c} .
$$

To make him willing to borrow, it must be that

$$
\frac{y+\left(\phi-R_{0}\right) I}{R_{1}}+a \bar{c} \geq y+\left(\phi-R_{0}\right) I
$$

Note that since $R_{1}>1$, increasing $R_{0}$ relaxes this constraint and makes it possible to raise $R_{1}$.

The lender's net earnings from $L_{0}$ and $L_{1}$ in this case are given by

$$
\begin{aligned}
& I R_{0}-I \rho^{2}+y+\left(\phi-R_{0}\right) I-\frac{\rho}{R_{1}}\left(y+\left(\phi-R_{0}\right) I\right) \\
= & -I \rho^{2}+y+\phi I-\frac{\rho}{R_{1}}\left(y+\left(\phi-R_{0}\right) I\right) .
\end{aligned}
$$

For any fixed value of $R_{1}$, this expression is clearly increasing in $R_{0}$. Moreover as observed above, raising $R_{0}$ allows the lender to raise $R_{1}$. This gives the lender a double incentive to raise $R_{0}$. However in setting $R_{0}$ he has to consider period zero's incentive constraint. Period zero will only put in the necessary effort in this scenario if

$$
\left[y+\frac{y+\left(\phi-R_{0}\right) I}{R_{1}}-\bar{c}\right]-E \geq 0 .
$$

which tells us that

$$
\frac{y+\left(\phi-R_{0}\right) I}{R_{1}} \geq \bar{c}+E-y
$$

Using this in the expression for the lender's profits gives us the following upper bound for the lender's profits

$$
y+\left(\phi-\rho^{2}\right) I-\rho(\bar{c}+E-y) .
$$

Can this be less than $y$, which was the lender's profit in the absence of investment? Clearly this depends on how large $E$ can be. The constraint on $E$ comes from feasibility. Since $R_{1}^{o}=\infty$, the agent does not borrow in period 1, and the feasibility constraint is simply

$$
2 y+\left(\phi-\rho^{2}\right) I-\bar{c}-E \geq 0
$$

Suppose this constraint is only just satisfied, so that

$$
2 y+\left(\phi-\rho^{2}\right) I=\bar{c}+E
$$

Substituting this into the upper bound on the lender's profits, we get

$$
\bar{c}+E-y-\rho(\bar{c}+E-y)
$$


which is negative. Clearly there is a range of values of parameters for which the lender would never choose this option.

Finally consider the case where the lender gives up trying to lend in period 1 and simply tries to extract enough using $R_{0}$. In this case the lender's profit is simply

$$
\left(R_{0}-\rho^{2}\right) I \text {. }
$$

The constraint on $R_{0}$ comes from period zero's incentive constraint, which is

$$
\begin{aligned}
2 y+\left(\phi-R_{0}\right) I-\bar{c}-E & \geq 0 \\
2 y+\phi I-\bar{c}-E & \geq R_{0} I
\end{aligned}
$$

Obviously in the case where the feasibility constraint is just satisfied, this reduces to the constraint $R_{0} I \leq \rho^{2} I$. The lender makes no money. Hence he would prefer to block the investment by setting $R_{0}$ very high.

A simple corollary follows immediately from this the proof of this proposition:

Corollary 10 Suppose the investment does not cost any money i.e. $I=0$. However the money-lender can somehow block the agent's access to the investment (by using his political power for example). Under NDTC he will never exercise this option. However under DTC there exist situations where he will choose to block access to the investment.

\section{Empirical Tests of the Model}

The above propositions provide qualitative predictions. However, the model also lends itself to a few specific quantitative tests. Here we outline how those tests might work.

First, it may be possible to use observational data to test some of the assumptions of the model. In particular, we could use exogenous income shocks to look at which goods are the most income elastic and how the elasticities vary for the rich and the poor. Then we can ask whether the goods for which the income elasticities are systematically higher for the poor than for the rich are the same goods that in surveys, people claim to want to give up.

Second, we can actually test whether temptation is in fact declining. To do this, suppose there are several goods $g_{i}$. Suppose that each good has an $x$ component and a $z$ component. Specifically, suppose that one unit of good $i$ provides $x_{i}$ fraction of the non-temptation and $z_{i}$ fraction of the temptation good. Moreover, suppose that what constitutes $x$ and $z$ goods is common across individuals. ${ }^{37}$ Now consider the following experiment. Suppose that we offer to a set of individuals a choice between 1 unit of good $i$ and $d_{i}$ units of good $i$ in one period. Assume, as is common in all discount rate experiments, that there

\footnotetext{
${ }^{37} \mathrm{~A}$ weaker assumption that would still work is to assume there is a common component with individuals varying in an iid way around this common component.
} 
is non-fungibility across time and goods so that individuals view this offer as a genuine increase of either 1 unit today or $d_{i}$ units tomorrow. ${ }^{38}$ Define $\bar{d}_{i}$ to be the average $d_{i}$ that makes individuals indifferent to this trade-off, i.e. half the individuals choose 1 unit today and half choose $\bar{d}_{i}$ units in one period. These experiments allow us to array goods according to how much temptation they provide. Goods that provide more temptation should show larger $\bar{d}_{i}$ : one would need a large quantity in the future to induce one to give up one unit today. The key assumption of our model can be empirically tested by looking at the Engel curve for each good: declining temptations implies that the Engel curve should be steeper for goods with lower $\bar{d}_{i}$. Note that this is not mechanically true: The Engel curve captures how demand for a particular good varies with income, whereas $\bar{d}_{i}$ measures the discount rate associated with a particular good.

A final quantitative test of our model is based on our assertion that the apparent patience difference between poor and rich is due to the composition of consumption rather than genuine differences in patience. To test this, we would offer trade-offs of 1 unit of money today versus $d_{m}$ units tomorrow and use this to back out an apparent discount rate for money $\delta_{m}$. We would then offer (again, under the assumption of fungibility), 1 unit of an $x$ good (identified as above) today versus $d_{0}$ units tomorrow. This allows us to back out an apparent discount rate for $x$ goods $\delta_{x}$. We then predict that $\frac{\delta_{m}}{\delta_{x}}$ is declining in income: the poor are much more impatient in money than in $x$ goods and this gap closes as income increases.

Note that these procedures do not just provide a test of the model. They provide an important discipline to this approach. A key judgment needed to operationalize this model is the identification of temptation goods. Such identification can be particularly difficult since there are often large inter-personal differences in preferences. The above procedure provides a way to elicit an individual's own judgments about what constitutes a temptation good. Such judgments, we feel, will sometimes yield counterintuitive valuations. For example, when Ashraf, Karlan and Yin (2004) provide commitment savings accounts, they ask individuals what they are saving up to buy. Since one would only save up to buy $x$ goods, it is interesting to see that the second most common stated purpose for savings is festival and party expenditures. This might contrast with our intuitive sense that the poor "waste" their money on these expenditures. ${ }^{39}$ This example highlights the need for judicious use of experiments of the type above to determine what is a temptation good and what is a genuine oasis of pleasure.

\footnotetext{
${ }^{38}$ This assumption is common in all discount rate experiments that are undertaken for money, e.g. one dollar today or two dollars in one month. Such experiments are meaningless if money were fungible in time for example.

${ }^{39}$ Of course, to the extent that they generate a conspicuous consumption externality, there can still be an argument for social waste.
} 


\section{Conclusion}

We feel that understanding the structure of temptations ("wasted expenditures") is essential to understanding the lives of the poor. Our framework highlights one important structural feature of temptations: whether their impact is declining in income. The results in this paper illustrate that declining temptations can help to explain a large range of phenomena, from poverty traps to credit and investment behavior. Though we do not focus on these issues in this paper, they may also be helpful in answering a broader set of questions. First, we mentioned briefly the idea that understanding the structure of temptation may help in classifying and designing commitment savings products. Should these products force savings or limit withdrawals? Should they put a ceiling on withdrawals (so that there is always something left against emergencies or limit withdrawals until a minimum amount is reached (so as to enable the accumulation of a large lump sum)? We understand little empirically or theoretically about these questions. Second, while our model focuses on expenditures, many of the important choices of the poor are not fully captured by a pure expenditure focus. For example, the labor leisure choice is an important component of overall income and wealth accumulation. Understanding how these choices integrate into a temptation framework seems particularly important.Third, our model generates a non-convexity in the second period utility function as viewed from the perspective of the first period self. This might can provide a foundation for the utility function proposed by Friedman and Savage (1948) to rationalize the demand for lotteries among the poor. More generally the implications of our framework for the relation between measured and actual risk aversion seem potentially interesting and important. Finally, a deeper understanding of certain potentially addictive social behaviors, for example drinking and smoking, have the potential to be interesting but would require a greater investment in exploring the relation between the technology of addiction and aspects of the shape of temptation emphasized here. While the present model makes some progress, much interesting work remains to be done. 


\section{Appendix}

\subsection{Proof of Proposition 2}

Proof. Since $U^{\prime}\left(x^{2}\left(c^{2}\right)\right)=V^{\prime}\left(z^{2}\left(c^{2}\right)\right)$, and $x^{2}\left(c^{2}\right)+z^{2}\left(c^{2}\right)=c^{2}, \frac{d z^{2}}{d c^{2}}=\frac{U^{\prime \prime}\left(x^{2}\left(c^{2}\right)\right)}{V^{\prime \prime}\left(z^{2}\left(c^{2}\right)\right)+U^{\prime \prime}\left(x^{2}\left(c^{2}\right)\right)}$ and $\frac{d x^{2}}{d c^{2}}=\frac{V^{\prime \prime}\left(z^{2}\left(c^{2}\right)\right)}{V^{\prime \prime}\left(z^{2}\left(c^{2}\right)\right)+U^{\prime \prime}\left(x^{2}\left(c^{2}\right)\right)}$. Taking derivatives and substituting the values of $\frac{d x^{2}}{d c^{2}}$ and $\frac{d z^{2}}{d c^{2}}$ gives us

$$
\frac{d^{2} z^{2}}{d\left(c^{2}\right)^{2}}=\frac{\left(V^{\prime \prime}\right)^{2} U^{\prime \prime \prime}-\left(U^{\prime \prime}\right)^{2} V^{\prime \prime \prime}}{\left(U^{\prime \prime}+V^{\prime \prime}\right)^{3}}
$$

Now define $H$ such that $\widetilde{V}\left(x^{2}\right)=V\left(z^{2}\left(x^{2}\right)\right)=H\left(U\left(x^{2}\right)\right)$. Taking derivatives and using the fact that $\frac{d z^{2}}{d x^{2}}=\frac{U^{\prime \prime}}{V^{\prime \prime}}$ gives us that

$$
H^{\prime}(U)=\frac{V^{\prime} U^{\prime \prime}}{U^{\prime} V^{\prime \prime}}
$$

Taking derivatives again gives us that

$$
H^{\prime \prime}(U)=\frac{1}{U^{\prime}}\left[\frac{U^{\prime} V^{\prime \prime}\left(V^{\prime} U^{\prime \prime \prime}+V^{\prime \prime} U^{\prime \prime} \frac{d z^{2}}{d x^{2}}\right)-V^{\prime} U^{\prime \prime}\left(U^{\prime} V^{\prime \prime \prime} \frac{d z^{2}}{d x^{2}}+U^{\prime \prime} V^{\prime \prime}\right)}{\left(U^{\prime} V^{\prime \prime}\right)^{2}}\right] .
$$

Since $V^{\prime}=U^{\prime}$, this reduces to

$$
H^{\prime \prime}(U)=\frac{V^{\prime}}{V^{\prime \prime}}\left[\frac{\left(V^{\prime \prime}\right)^{2} U^{\prime \prime \prime}-\left(U^{\prime \prime}\right)^{2} V^{\prime \prime \prime}}{\left(U^{\prime} V^{\prime \prime}\right)^{2}}\right] .
$$

Since $\left(U^{\prime \prime}+V^{\prime \prime}\right)^{3}$ has the same sign as $V^{\prime \prime}$, the result follows.

\subsection{A Derived Hyperbolic Model}

To see the similarities, therefore, consider a T-period extension of our model.

Under assumptions that gave us (3), the intertemporal maximand for this case can be written in the form

$$
U\left(x^{1}\right)+V\left(z^{1}\right)+\sum_{t=1}^{T} \delta^{t} E\left\{U\left(x^{t}\right)\right\}
$$

Maximizing $U(x)+V(z)$ subject to a budget constraint $x+z=c$, and the conditions $(x \geq 0, z \geq 0)$ gives us a function $x(c)$.

$$
\begin{aligned}
\widetilde{U}(c)= & U(x(c)) \\
& \text { and } \\
\widetilde{V}(c)= & V(z(c))
\end{aligned}
$$

Then the above expression becomes

$$
\widetilde{U}\left(c^{1}\right)+\widetilde{V}\left(c^{1}\right)+\sum_{t=2}^{T} \delta^{t} E\left\{\widetilde{U}\left(c^{t}\right)\right\}
$$


When $\widetilde{V}(c)=\alpha \widetilde{U}(c)$, this is the standard $\beta-\delta$ utility function with $\beta=\frac{1}{1+\alpha}$. One case where this condition holds is when

$$
\begin{aligned}
U\left(x_{t}\right) & =\frac{x_{t}^{1-\alpha}}{1-\alpha} \text { and } \\
V\left(z_{t}\right) & =A \frac{z_{t}^{1-\alpha}}{1-\alpha} .
\end{aligned}
$$

In other words two essentially identical CRRA functions: Under these assumptions, within period choice between $x$ and $z$ will give us $z_{t}=q x_{t}$ where $q=A^{\frac{1}{\alpha}}$. Substituting this into our maximand gives us

$$
\begin{aligned}
& \frac{x_{0}^{1-\alpha}}{1-\alpha}+\frac{(q)^{1-\alpha} x_{0}^{1-\alpha}}{1-\alpha}+\sum \delta^{t} \frac{x_{t}^{1-\alpha}}{1-\alpha} \\
= & \left(1+q^{1-\alpha}\right)\left[\frac{x_{0}^{1-\alpha}}{1-\alpha}+\sum \beta \delta^{t} \frac{x_{t}^{1-\alpha}}{1-\alpha}\right]
\end{aligned}
$$

where $\beta=\frac{1}{1+q^{1-\alpha}}$, which is exactly in the hyperbolic form.

More generally, the models will be distinct, since they represent different assumptions about temptation. The hyperbolic model focuses on disagreements about the level of consumption whereas our model focuses on disagreements about the composition of consumption. There are two ways to understand this difference. First, we could start by assuming that our model is the more accurate model of temptation-that temptation in fact occurs at the level of individual goods. In this case, the hyperbolic model should be seen as a convenient approximation to the T-period version of our model and $\beta$ in those models is an approximation to a more endogenously determined myopia factor (such as the temptation tax in our model). Alternately we could start from the premise that the hyperbolic model is the right framework but in util space: individuals value more utils today than the long-run self would want them to. Different goods provide different time-profiles of hedonic flows. Hence some goods are more tempting because they provide more present utils relative to the long-run utils they provide. Our model then is a reduced form that abstracts from the differential time-flow of utils. In this paper, we do not attempt to distinguish between these alternative positions and simply work with our $U(x)$ and $V(z)$ framework for the rest of the paper.

\subsection{Generalizing the idea of the temptation good}

So far we have operated on different preferences for two index goods. A more realistic assumption would be that people have different preferences over a set of goods. To get at this idea, denote by $u^{F}\left(x_{1}, \ldots, . x_{n}\right)$ the utility function that represents the preferences of the forward-looking self over any future outcomes, and by $u^{T}\left(x_{1}, \ldots, x_{n}\right)$ the utility of the current self over current outcomes; both utility functions are now defined over the same set of goods. $u^{T}$ is where the temptations come in (hence the superscript). 
Let $x^{T}(c)$ be the vector of goods that maximizes $u^{T}\left(x_{1}, \ldots, x_{n}\right)$ subject to $\sum_{i=1}^{n} x_{i}=c$. Define $w^{T}(c)$ to be the indirect utility of the tempted utility function: $w^{T}(c)=u^{T}\left(x^{T}(c)\right)$. Given this definition it is easy to write the maximization problem of the forward-looking decision-maker as one of choosing $\left(c^{1}, c^{2}\right)$ to maximize

$$
u^{T}\left(x^{T}\left(c^{1}\right)\right)+\delta u^{F}\left(x^{T}\left(c^{2}\right)\right)
$$

subject to the intertemporal budget constraint. It is clear that the slope of the $u^{P}$ function relative to the slope of the of $u^{T}$ function plays a role similar to the discount factor. We impose the assumption that this does not cause any bias towards the future:

$$
\sum_{i} \frac{\partial u^{T}\left(x_{i}^{T}(c)\right)}{\partial x_{i}} \frac{\partial x_{i}^{T}(c)}{\partial c} \geq \sum_{i} \frac{\partial u^{P}\left(x_{i}^{T}(c)\right)}{\partial x_{i}} \frac{\partial x_{i}^{T}(c)}{\partial c}, \text { for all } c .
$$

Note that both sides of this inequality are evaluated at the same value of $c$.

Assume for the sake of the exposition that the decision maker has a fixed endowment $y$ that he gets in the first period, no second period earnings, and can lend at the rate $r$. Then the first order condition for this maximization problem will be

$$
\frac{d w^{T}\left(c^{1}\right)}{d c}=\delta r \sum_{i} \frac{\partial u^{P}\left(x_{i}^{T}\left(c^{2}\right)\right)}{\partial x_{i}} \frac{\partial x_{i}^{T}\left(c^{2}\right)}{\partial c} .
$$

It turns out that this decision maker would behave exactly like a $U-V$ decision maker with appropriately chosen $U$ and $V$ functions. To see this, note that this would require that the $U(x)$ function and the $x(c)$ function satisfy

$$
U^{\prime}\left(x\left(c^{2}\right)\right) x^{\prime}\left(c^{2}\right)=\sum_{i} \frac{\partial u^{P}\left(x_{i}^{T}\left(c^{2}\right)\right)}{\partial x_{i}} \frac{\partial x_{i}^{T}\left(c^{2}\right)}{\partial c}
$$

and

$$
U^{\prime}\left(x\left(c^{1}\right)\right)=\frac{\partial w^{T}\left(c^{1}\right)}{\partial c}
$$

Putting these together gives us that $x(c)$ needs to satisfy the differential equation:

$$
x^{\prime}(c)=\frac{\sum_{i} \frac{\partial u^{P}\left(x_{i}^{T}(c)\right)}{\partial x_{i}} \frac{\partial x_{i}^{T}(c)}{\partial c}}{\frac{\partial w^{T}(c)}{\partial c}}
$$

which pins down $x(c)$ if we impose the boundary condition $x(0)=0 . x(c)$ is clearly an increasing function and therefore has an inverse function $c^{-1}(x)$. Moreover since

$$
\frac{\partial w^{T}(c)}{\partial c}=\sum_{i} \frac{\partial u^{T}\left(x_{i}^{T}(c)\right)}{\partial x_{i}} \frac{\partial x_{i}^{T}(c)}{\partial c} \geq \sum_{i} \frac{\partial u^{P}\left(x_{i}^{T}(c)\right)}{\partial x_{i}} \frac{\partial x_{i}^{T}(c)}{\partial c}
$$

by our above assumption, $x^{\prime}(c) \leq 1$ for all $c$. 
And given $c^{-1}(x), U(x)$ can be defined according to:

$$
U^{\prime}(x)=\frac{\partial w^{T}}{\partial c}\left(c^{-1}(x)\right)
$$

along with the boundary condition

$$
U(0)=w^{T}(0) .
$$

It is true that we have not yet defined $V(z)$ but this is not an issue because Proposition 8.3 below tells us that as long as $x(c)$ is increasing and less than or equal to $c$ for all values of $c$ (both properties that have already been verified above for the $x(c)$ function we constructed) ${ }^{40}$ there is always an increasing and concave $V(z)$ function, such that maximizing $U(x)+V(z)$ subject to $x+z=c$ will give us that particular $x(c)$ function.

To summarize, the model where both selves care about all the goods (but not to the same extent) is observationally equivalent to a model with $U-V$ preferences (as long as we only observe total expenditures in each period, as opposed to the amount spent on each good), for an appropriate choice of $U$ and $V$. This ought to be intuitive: essentially, $x$ captures the part of the expenditure that aligns with what the forward-looking self wants, while $z$ is the part that is wasted from the forward-looking self's point of view, and it should not matter that the wasted expenditure takes the form of excess spending on goods that the forward-looking self also values (just not enough to justify that level of spending).

An implication of this reformulation is that the same good may end up being a temptation good in some contexts but not in others. For example, it is not implausible that for some poor people, calorie-rich food is a necessity and fancy exercise machines are temptation goods, while the reverse is true of some wealthy and overweight people.

\section{References}

[1] Aleem, Irfan (1990). "Imperfect Information, Screening, and the Costs of Informal Lending: A Study of a Rural Credit Market in Pakistan", World Bank Economic Review, 4 (3): 329-349.

[2] Ashraf, Nava, Dean Karlan and Wesley Yin (2006). "Tying Odysseus to the Mast: Evidence from a Commitment Savings Product in the Philippines", Quarterly Journal of Economics, 121 (2): 635-672.

[3] Banerjee, Abhijit and Esther Duflo (2006). "The Economic Lives of the Poor", Journal of Economic Perspectives, 21 (1): 141-167.

[4] Banerjee, Abhijit and Andrew F. Newman (1993). "Occupational Choice and the Process of Development", Journal of Political Economy, 101 (2): $274-298$.

${ }^{40} x(c) \leq c$ follows from the fact that $\frac{d x(c)}{d c} \leq 1$ and $x(0)=0$. 
[5] Becker, Gary S and Casey Mulligan, (1994). "On the Endogenous Determination of Time Preference," mimeo, University of Chicago.

[6] Douglas Bernheim, Debraj Ray and Sevin Yeltekin, (1999), "Self Control, Saving and the Low Asset Trap", mimeo, New York University.

[7] Bhaduri, Amit (1977). "On the formation of usurious interest rates in backward agriculture", Cambridge Journal of Economics, 1 (4): 341-352.

[8] Collins, D., J. Morduch, S. Rutherford, and O. Ruthven (2009). Portfolios of the Poor: How the World's Poor Live on \$2 a Day, Princeton: Princeton University Press.

[9] de Mel, Suresh, David McKenzie and Christoper Woodruff (2008). "Returns to Capital in Microenterprises: Evidence from a Field Experiment", Quarterly Journal of Economics, 123 (4): 1329-1372.

[10] Dreze, Jean, Peter Lanjouw, and Naresh Sharma (1997). "Credit in Rural India: A Case Study", LSE STICERD Research Paper, DEDPS06.

[11] Duflo, Esther, Michael Kremer and Jonathan Robinson (2009). "Nudging Farmers to Use Fertilizer: Evidence from Kenya", Working Paper.

[12] Fisher, Irving (1932). Booms and Depressions, Some First Principles, New York: Adelphi Company.

[13] Friedman, Milton and Leonard Savage, (1948) " "Utility Analysis of Choices Involving Risk" with Leonard Savage, 1948, Journal of Political Economy Vol. 56, No. 4, Aug, pp. 279-304

[14] Fudenberg, Drew and David K. Levine (2006). "A Dual Self Model of Impulse Control", American Economic Review, 96 (5): 1449-1476.

[15] Galor, Oded and Joseph Zeira (1993). "Income Distribution and Macroeconomics", Review of Economic Studies, 60: 35-52.

[16] Gruber, Jonathan and Botond Koszegi (2001). "Is Addiction "Rational"? Theory and Evidence", Quarterly Journal Economics, 116 (4): 1261-1303.

[17] Gugerty, Mary K. (2007). "You Can't Save Alone: Commitment in Rotating Savings and Credit Associations in Kenya", Economic Development and Cultural Change, 55: 251-282.

[18] Harris, Christopher and David Laibson (2001). "Dynamic Choices of Hyperbolic Consumers", Econometrica, 69 (4): 935-957.

[19] Karlan, Dean and Sendhil Mullainathan (2009). "Debt Cycles", Work in Progress.

[20] Laibson, David (1997). "Golden Eggs and Hyperbolic Discounting", Quarterly Journal of Economics, 112 (2): 443-477. 
[21] Lee, Jean, Michael Kremer and Jonathan Robinson (2009). "The Return to Capital for Small Retailers in Kenya: Evidence from Inventories", Working Paper.

[22] McClure, S. M., D. I. Laibson, G. Loewenstein and J. D. Cohen (2004). "Separate Neural Systems Value Immediate and Delayed Monetary Rewards", Science, 306 (5695): 503-507.

[23] Katherine L. Milkman, Todd Rogers, Max H. Bazerman (2010), I'll have the ice cream soon and the vegetables later: A study of online grocery purchases and order lead time, Marketing Letters 21(1), 17-36.

[24] Katherine L. Milkman, Todd Rogers, Max H. Bazerman (2009), Highbrow films gather dust: Time-inconsistent preferences and online DVD rentals, Management Science, 55(6), 1047-1059

[25] O'Donoghue, Ted and Matthew Rabin (1999). "Doing it Now of Later", American Economic Review, 89 (1): 103-124.

[26] O’Donoghue, Ted and Matthew Rabin (2006), "Optimal sin taxes", mimeo, Cornell University.

[27] Ray, Debraj, (2002), "Aspirations, Poverty and Economic Change", mimeo, New York University.

[28] Daniel Read; George Loewenstein; Shobana Kalyanaraman (1999), "Mixing virtue and vice: Combining the immediacy effect and the desire for diversity", Journal of Behavioral Decision Making,12(4), 257-273.

[29] Skiba, Paige M. and Jeremy Tobacman (2007). "Measuring the IndividualLevel Effects of Access to Credit: Evidence from Payday Loans", Proceedings Federal Reserve Bank of Chicago, May: 280-301.

[30] Srinivasan, T. N. (1979). "Agricultural Backwardness Under SemiFeudalism," Economic Journal 89(354), June: 416-19

[31] Subramanian, Shankar and Angus Deaton (1996). "The Demand for Food and Calories", Journal of Political Economy, 104 (1): 133-162.

[32] Thaler, Richard H. and H. M. Shefrin (1981). "An Economic Theory of Self-Control", Journal of Political Economy, 89 (2): 392-406.

[33] Udry, Christopher and Santosh Anagol (2006). "The Return to Capital in Ghana", American Economic Review, 96 (2): 388-393. 